\title{
Homogeneous Charge Compression Ignition (HCCI) Combustion Engine- A Review
}

\author{
Pravin Kumar ${ }^{1}$, A. Rehman ${ }^{2}$ \\ ${ }^{1}$ (Research scholar, Dept. of Mechanical Engineering., Maulana Azad National Inst. of Tech., Bhopal, India) \\ ${ }^{2}$ (Professor, Dept. of Mechanical Engineering, Maulana Azad National Inst. of Tech., Bhopal, India)
}

\begin{abstract}
At present, it is highly required from the automobile sector to develop clean technologies with lower fuel consumption for ambient air quality improvement, green house gas reduction and energy security. Furthermore, due to continuously stringent emission legislation and the fast depletion of the primary energy resources, the development of new highly efficient and environment friendly combustion systems becomes of paramount importance and hence research need to be done in this area. One such combustion system is Homogeneous Charge Compression Ignition (HCCI) technology, which has the potential to reduce oxides of nitrogen (NOx) and particulate matter (PM) simultaneously maintaining the thermal efficiency at par with that of conventional diesel engine combustion. However, some issues such as combustion phasing control, controlled auto-ignition, operating range, homogeneous charge preparation, cold start, pressure rise rate and noise and emissions of unburned hydro carbon (UHC), and carbon monoxide (CO) need to be solved for successful operation and therefore commercial application of HCCI engine. Other similar combustion concepts, which can be considered as the extension of HCCI, are Low Temperature Combustion (LTC) and Stratified Charge Compression Ignition (SCCI). This paper reviews all the three advanced combustion concepts along with their merits and demerits.
\end{abstract}

Keywords: HCCI, LTC, NOx, PM, SCCI

\section{Introduction}

It is highly required from the automobile sector to develop clean technologies with lower fuel consumption for the improvement of the ambient air quality, reduction of the green house gases, security of the primary energy resources and fulfilment of the increasingly stringent emission norms. Therefore, the fuel and the engines used in transportation sector have to cope up with two major challenges of improving efficiency and reducing emissions in a highly competitive era $[\mathbf{1 , 2}]$.

Compression Ignition (CI) and Spark Ignition (SI) combustion are two primary technologies with established use in automobile sector. SI and CI engines use fossil fuels and both have their own merits and demerits [3]. The characteristic feature of traditional SI engine is flame propogation for combustion. A conventional SI engine uses a homogeneous fuel/air mixture, which is prepared in the intake port and then undergoes induction compression. This homogeneous mixture is ignited by the spark discharge given theoretically at the end of the compression stroke. The start of combustion in SI engines is governed by varying the spark discharge timing. As the SI engines use fixed air/fuel ratio, therefore the engine load regulation is made possible only by governing the air mass flow into the combustion chamber. The throttle used for this purpose results in pumping losses and reduction in efficiency. It produces extremely low soot emissions because it uses premixed charge with stoichiometric fuel-air ratio $(\lambda=1)$, but it also has lower thermal efficiency due to pumping loss and a lower compression ratio (generally in the range of 8 to 12), which is limited by knocking. Hence, SI engines with accurate control of air-fuel ratio and three way catalytic convertors are very clean power producing machines but their efficiency is limited because of throttling, knocking and the lean flammability limits On the other hand, a conventional CI engine uses a heterogeneous fuel/air mixture. The air alone is sucked in the suction stroke. And the fuel is injected directly and rapidly into the combustion chamber theoretically at the end of the compression stroke. This injected fuel is then auto-ignited after a short delay time. The processes, which take place between the fuel injection and the start of combustion events are cumbersome, which include droplet formation, collisions, break-up, evaporation. The rate of combustion is affected by these processes. In CI engines, only a fraction of the air and fuel is premixed and burns fast, whereas for the larger part of the fuel, the time scale of evaporation, diffusion etc. is more than the chemical time scale. Hence, the airfuel mixture within the combustion chamber can be divided into two regions- the high fuel concentration regions and the high temperature flame regions. In the fuel rich regions, the rate of soot formation is high due to absence of oxygen $\left(\mathrm{O}_{2}\right)$. Though, some soot may be oxidized with the increase in in-cylinder temperature. NOx is produced at high rates in the high temperature regions. In a traditional diesel engine, the cylinder temperature is about $2700 \mathrm{~K}$. In the $\mathrm{CI}$ engines, there is less pumping loss and the higher efficiency due to higher compression ratio (generally in the range of 12 to 24). CI engines are very efficient power producing machines, 
but they have a constraint in the form of trade-off between oxides of nitrogen (NOx) and Particulate Matter (PM) emissions. Therefore, it is necessary to keep the maximum cylinder temperature low in order to minimize the NOx emission and also to promote better fuel-air mixing in order to reduce the smoke emissions $[\mathbf{2 , 4 , 5 , 6 ]}$. However, CI engines are widely used for personal as well as commercial transportation due to their excellent fuel economy. Both CI and SI engines are major contributors to urban air pollution. Carbon mono-oxide (CO) and unburnt hydrocarbons (UBHC) emissions from these engines contribute to global warming. Oxides of nitrogen and hydrocarbons emitted from these engines react in atmosphere to form photochemical smog, particulate matter emitted from diesel engines causes asthma and respiratory episodes. Due to adverse impact of these pollutants on human health, increasingly stringent emission legislations are being enforced throughout the world, which require simultaneous reduction of PM and NOx emissions [3]. It has been indicated by some of the researchers that the fuel economy of the conventional piston engines has the possibility for further improvement by $25 \%$ or more while lowering the harmful emissions to near zero level by applying advanced combustion technologies [4].

Some of the next generation advanced combustion concepts, which have the potential to reduce NOx and PM emissions simultaneously while maintaining high thermal efficiency are- Homogeneous Charge Compression Ignition (HCCI), Stratified Charge Compression Ignition (SCCI) and Low Temperature Combustion (LTC) among others.

\subsection{HCCI principle}

\section{Fundamentals of HCCI Combustion}

In HCCI mode of combustion, the fuel and air are mixed prior to the start of combustion and the mixture is auto-ignited spontaneously at multiple sites throughout the charge volume due to increase in temperature in the compression stroke $[\mathbf{4 , 6 , 7 ]}$. In this mode, the combustion process is arranged in such a way that the combustion takes place under very lean and dilute mixture conditions, which results in comparatively lower bulk temperature and localised combustion temperature, which therefore, considerably reduces the NOx emissions. Furthermore, unlike conventional CI combustion, in HCCI mode the fuel and air is well mixed (homogeneous). So, the absence of fuel rich regions in the combustion chamber results in considerable reduction in PM generation. Therefore, due to absence of locally high temperatures and a rich fuel-air mixture during combustion process, the simultaneous reduction of NOx and PM emissions is made possible $[\mathbf{5 , 7 , 8 ]}$.

Table 1 Comparison of Traditional and HCCI Combustion Modes [4]

\begin{tabular}{|lccc|}
\hline & SI & CIDI & HCCI \\
Fuel & (gasoline-like fuel) & (diesel-like fuel) & (flexible fuel) \\
\hline$\lambda$ & PFI, GDI & $=1.2-2.2$ & $>1.0$ \\
$\begin{array}{l}\text { Mixture preparation } \\
\text { Ignition }\end{array}$ & DI & DI, PFI \& DI+PFI \\
Combustion form & Premixed & Auto-ignition & Duto-ignition \\
& & Diffusion & by chemical kinetics \\
Combustion rate limitation & Flame propogation & Mixing rate & Multipoint or spontaneous \\
Flame front & Yes & Yes & Without \\
Combustion temperature & High & Partially high & Relatively low \\
& & & \\
& & & \\
& & & \\
\end{tabular}

Table 1 gives a brief comparison of the characteristic features of SI, CIDI and HCCI combustion modes. The advantages of HCCI combustion can be summarized as follows:

1. HCCI combustion uses a higher compression ratio, lacks a threshold value and has a shorter combustion period and faster combustion rate. Thus, it nearly achieves constant volume combustion and a higher thermal efficiency because of lower combustion temperature and lower radiation loss.

2. There is no flame front or flame spread or local regions of excessively high temperature and rich mixture, thereby reducing soot and NOx generation to a very low level.

3. Variety of fuel types can be used in this mode of combustion [4]. 


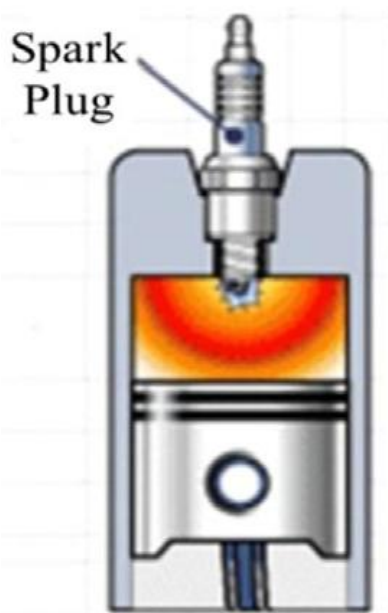

SI Engine

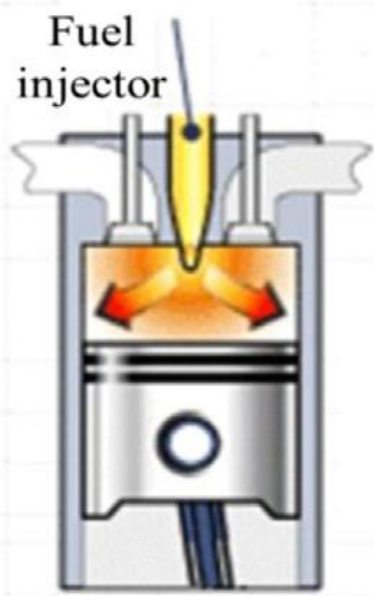

CI Engine

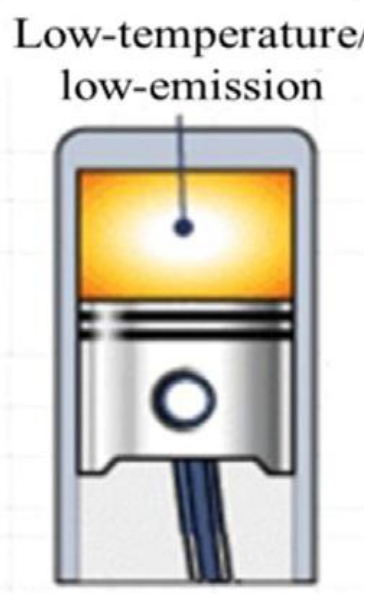

HCCI Engine

Fig. 1 Schematic diagram of HCCI combustion [9]

Fig. 1 represents the comparison among SI, CI and HCCI operations. In HCCI engines, a lean homogeneous flammable mixture (fuel-air equivalence ratio $\Phi<1$ ) is formed, before the start of ignition and is auto ignited as a result of increase in temperature in the compression stroke [10]. The HCCI operation is similar to SI engine as both use the homogeneous charge for combustion and similar to $\mathrm{CI}$ engine as both depend on the auto ignition of the mixture. Thus, HCCI combustion can be regarded as the hybrid of SI and CI combustion processes [11]. In SI engines, three zones of combustion namely burnt zone, unburned zone and a thin flame reaction zone in-between are generated for turbulent flame propagation through the cylinder. In CI engines, fuel is diffused into the cylinder and a definite diffusion flame traverses within the cylinder. Whereas, in HCCI engine spontaneous auto-ignition of whole cylinder mixture at multiple sites occurs without any diffusion flame or flame front propagation $[\mathbf{1 2}, \mathbf{1 3}]$.

Theoretically, diesel fuelled HCCI combustion has the potential to reduce PM and NOx emissions to near-zero level by employing two basic processes: firstly, by forming a homogeneous mixture and secondly, by auto-igniting this mixture due to compression heat.

However, these same features also lead to the main challenges. As diesel fuel possesses high viscosity, a wide range of boiling points, and a high cetane number. It means that the required mixing time scale for forming a homogenous mixture is very long but the chemical ignition time scale is very short [14]. Furthermore, fuel-wetting of diesel-fuelled HCCI combustion is also an issue under consideration [4].

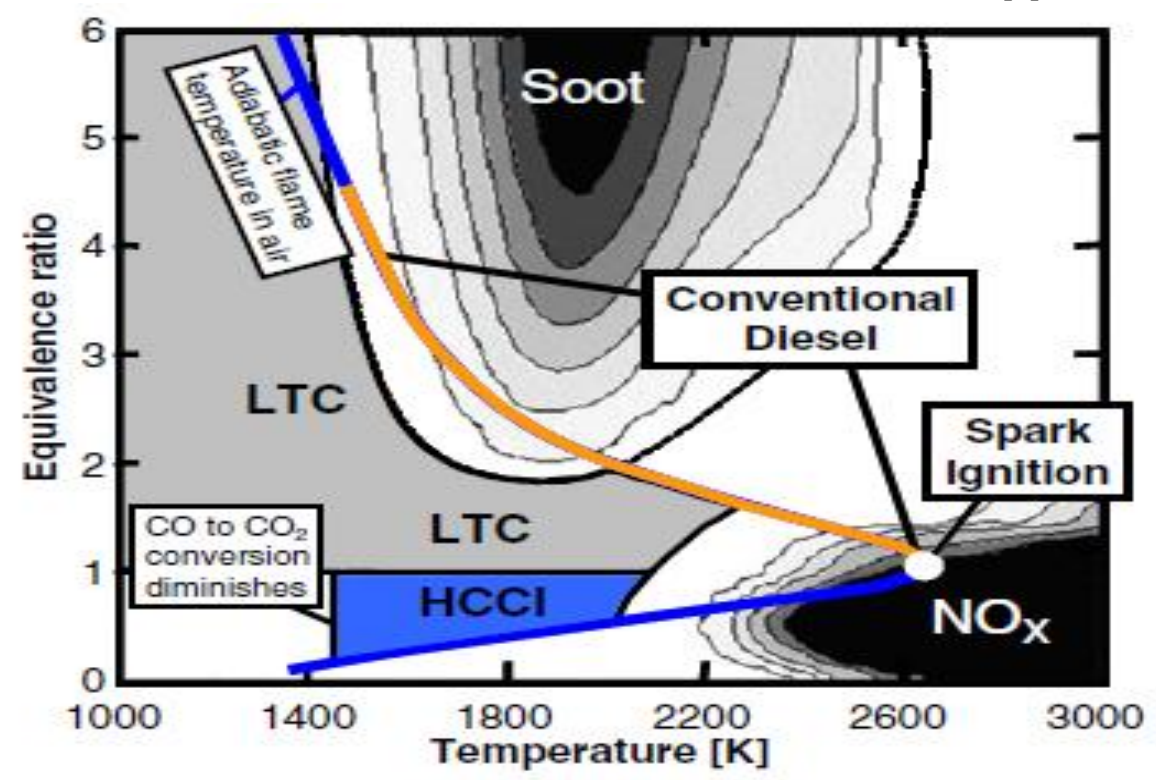

Fig. 2 - Conventional combustion \& variants of diesel combustion on T- $\Theta$ space [15]

As it is evident from Fig. 2 that for conventional diesel combustion, the adiabatic flame temperature in air stretches through both the soot and NOx generation regions. Conceptually, in a conventional diesel combustion, the fuel and air charge undergoes rich combustion of about $\theta=4$ at the end of the adiabatic mixing 
process during the ignition delay period, and then combustion moves to completion in a stoichiometric $(\theta=1)$ diffusion flame. This rich combustion may cause soot production depending upon the soot formation tendency of the fuel and the $\theta-T$ distribution during the pre-mixed combustion period. Once the combustion of the fuel prepared to flammability limits during the ignition delay period is over, the rate of combustion further depends on a mixing controlled basis. In the conventional diesel combustion, thermal $\mathrm{NO}_{\mathrm{x}}$ is produced when the local incylinder temperatures are in excess of 1800-2000 $\mathrm{K}$ and there is enough oxygen available. Considering approximately adiabatic combustion, these combustion regions fall in soot and NOx regions respectively, resulting in high levels of emissions. SI combustion also generates significant amount of NOx emissions, but they are removed by modern three-way catalysts. As it is clear from Fig. 2 that the HCCI combustion falls outside the soot and NOx islands. In HCCI combustion as the flame temperatures are considerably lower than the conventional diesel combustion due to lean or diluted mixture, the NOx emissions are low. Furthermore, the well premixed charge present in the cylinder leads to lower soot emissions as well. However, it is not necessary for combustion process to happen specifically in the HCCI region to avoid NOx and soot formation. Low Temperature Combustion (LTC) takes benefit of this fact by adjusting combustion to take place anywhere in the gray shaded region, while making effort to ensure that most of the fuel is mixed to $\theta \leq 1$ (the HCCI region), before the reactions are quenched by expansion for maintaining good combustion efficiency. Therefore, though diesel LTC combustion is not fully premixed, it employs necessarily the same principles as HCCI to achieve low emissions $[\mathbf{1 5}, \mathbf{1 6}]$.

\section{Challenges of HCCI Combustion}

In spite of several inherent advantageous features of HCCI combustion, there are some unresolved issues that have kept the HCCI engine from being applied in commercial engines. The most difficult hurdle is the control of ignition. The control of ignition is principally more problematic as compared to the direct control mechanism such as spark plug or fuel injector used in SI and CI engines respectively to control the ignition timing. In HCCI mode, the ignition is controlled by the charge mixture composition and its temperature history $[4,17]$. The main challenges of HCCI combustion are stated as follows:

\subsection{The difficulty in combustion phasing control}

Unlike conventional combustion mode as in SI and CI engines, the HCCI combustion lacks in direct method for controlling the combustion. In fact, in HCCI the start of combustion depends upon the auto-ignition chemistry of the mixture, which therefore is affected by the properties and the time-temperature history of the mixture. Therefore, the combustion phasing in HCCI engines is influenced by the several factors like autoignition properties of the fuel, fuel concentration, residual rate and possibly, reactivity of the residual, homogeneity of the mixture, compression ratio, intake temperature, latent heat of vaporization, engine temperature, heat transfer to the engine and other engine dependent parameters. [18-20].

\subsection{High levels of UHC \& CO emissions}

HCCI combustion generates inherently lower NOx and PM emissions at low loads but comparatively higher $\mathrm{HC}$ and $\mathrm{CO}$ emissions at low to medium loads as well as high NOx at high loads. In this mode a large fraction of the in-cylinder fuel is accumulated in the cylinder crevice region during the compression stroke and is therefore remains unburned. Furthermore, the larger part of this unburned fuel still remains unburned when it re-enters into the cylinder during the expansion stroke, as the temperature of the burned gas is too low. This leads to considerable increase in both $\mathrm{HC}$ and $\mathrm{CO}$ emissions as compared to the conventional combustion. Besides, the maximum temperature of the burned gas is not high enough (lower than $1400 \mathrm{~K}$ or $1500 \mathrm{~K}$ ) to oxidize the $\mathrm{CO}$ to $\mathrm{CO}_{2}$ at low loads and hence the combustion efficiency deteriorates $[18,19,21]$.

\subsection{Range of operation}

HCCI combustion performs satisfactorily only in the limited operating range. In this mode, controlling the ignition timing over the full range of speed and load is a challenging issue. The range of operation depends mainly on the auto-ignition properties of the fuel, engine geometry and the operating parameters. Part /light load operation suffers from the lack of sufficient ignition energy to auto-ignite the lean mixture at the end of the compression stroke. In addition, UHC and CO emissions also increase at part load operation due to insufficient combustion efficiency. Furthermore, the high load operation is typically limited by very high rate of pressure rise during combustion and therefore resulting engine knock $[10,15,18,19]$.

\subsection{Cold start capacity}

The HCCI ignition is very sensitive to the intake charge temperature and the small variations change the combustion phasing considerably. Furthermore, the initial temperature required to obtain auto-ignition condition changes with fuel properties and the operating conditions. HCCI engine will face a major problem in firing during cold start operations, as the temperatures are very low and the heat transfer to the cold combustion chamber walls is high. This problem can be overcome by starting the engine in a conventional mode and then switching over to the HCCI mode after a short warm-up period $[6,10,18,19]$. 


\subsection{Homogeneous mixture preparation}

Effective mixture preparation and avoiding fuel-wall wetting is the key to obtain high fuel efficiency, reduce $\mathrm{HC}$ and PM emissions and prevent oil dilution. Even for moderately volatile fuels like gasoline, wall wetting may adversely affect the $\mathrm{HC}$ emissions. This is specifically important for the poor volatile fuels like diesel. Mixture homogeneity affects the auto-ignition reactions, which control the combustion phasing. NOx emissions have found to be lower, even if there is some degree of inhomogeneity in the mixture $[10,18,19,23$, 24].

\subsection{Abnormal pressure rise with noise}

In HCCI mode, due to simultaneous auto-ignition of the whole homogeneous charge in the compression stroke, the heat release is instantaneous, which results in sudden rise in temperature followed by the abrupt rise in pressure leading to high levels of noise. Furthermore, at higher loads the rate of pressure rise can be so high that it may increase the engine noise considerably. If this condition is allowed to continue, then it may cause severe damage to the engine $[10,18,19,22,25]$.

\subsection{Prompt response of cycle transient}

HCCI suffers with a real-time, fast-response control system to tackle the challenges of maintaining required ignition timing during the transient operation, in which the engine speed and load fluctuates rapidly $[18,19]$.

\subsection{Engine control strategies and systems}

Still a lot of work is required to be done for developing a new methodology for feed-back and closedloop control of fuel and air systems, suitable control theory and control arithmetic, advanced combustion sensors and next-generation software and hardware accustomed for HCCI combustion in order to optimize the combustion process over full range of load and speed ranges $[18,19]$.

\subsection{Cylinder to cylinder variation}

Most of the theoretical and experimental work has been done on single cylinder engine. So, when HCCI was used in multi-cylinder engines, the ignition timing and combustion rate vary significantly due to variations in residual gas fraction, intake charge temperature, mass and composition of the fuel and air charge because of the structure and length of the manifolds. Hence, misfire may occur in certain cylinders and knock in other cylinders. Therefore, effort is required to be done for suitable designing of multi-cylinder engines to maintain precise uniformity of flows in every cylinder $[\mathbf{1 8}, \mathbf{1 9}]$.

\subsection{Accurate chemical mechanism and precise combustion model}

A multi-dimensional CFD model coupled with detailed chemical kinetics is required to be developed in order to fastly and inexpensively evaluate the engine geometry and combustion systems and therefore to accurately predict the features of HCCI combustion $[\mathbf{1 8}, \mathbf{1 9}]$.

\section{Main Approaches/Strategies for Mixture Preparation for Diesel Fuelled HCCI Combustion}

The preparation of the homogeneous mixture is the key in reducing the PM emissions and the local fuel-rich regions to minimize the NOx emissions. The local fuel-rich regions can be reduced by an effective mixture preparation. Due to very short span of time available for the preparation of the mixture, it becomes challenging to prepare a homogeneous mixture for cycle-to cycle variation of speed and load. The effective mixture preparation for the HCCI combustion refers to both the fuel-air homogeneity and temperature control during combustion. The various strategies for mixture preparation for diesel fuelled HCCI combustion has been shown in Fig. 3. The external mixture formation suffers with a drawback of low volumetric efficiency, whereas the in-cylinder mixture formation is prone to oil dilution $[4,10]$.

Diesel-fuelled HCCI combustion can be achieved with various methods such as high-pressure multiple injections, high density or high boosting, controllable EGR, variable compression ratio, flexible fuel-supplying strategies, variable valve actuation, and fuel-reforming technology.

Diesel-fuelled HCCI combustion can be classified into the following types: 1) external mixture formation or port fuel injection, 2) early direct injection based on the combination of fuel bumping, smalldiameter nozzle, narrow spray angle, and multiple injections, 3) late direct injection supplemented by a high level of EGR and high swirl ratio, and 4) compound HCCI combustion with PFI combined with early direct injection. It should be noted hereby that with reference to the typical nomenclature for diesel fuelled HCCI combustion, many researchers use the term Premixed-Charge Compression-Ignition (PCCI) because, theoretically, it is not possible to form a genuinely homogeneous mixture in such a short span of time [4]. External mixture preparation is a straight forward method for homogeneous mixture preparation for diesel fuelled HCCI combustion, whereas early and late direct injection strategies, though very effective, are more suitable for gasoline like fuels [7]. 


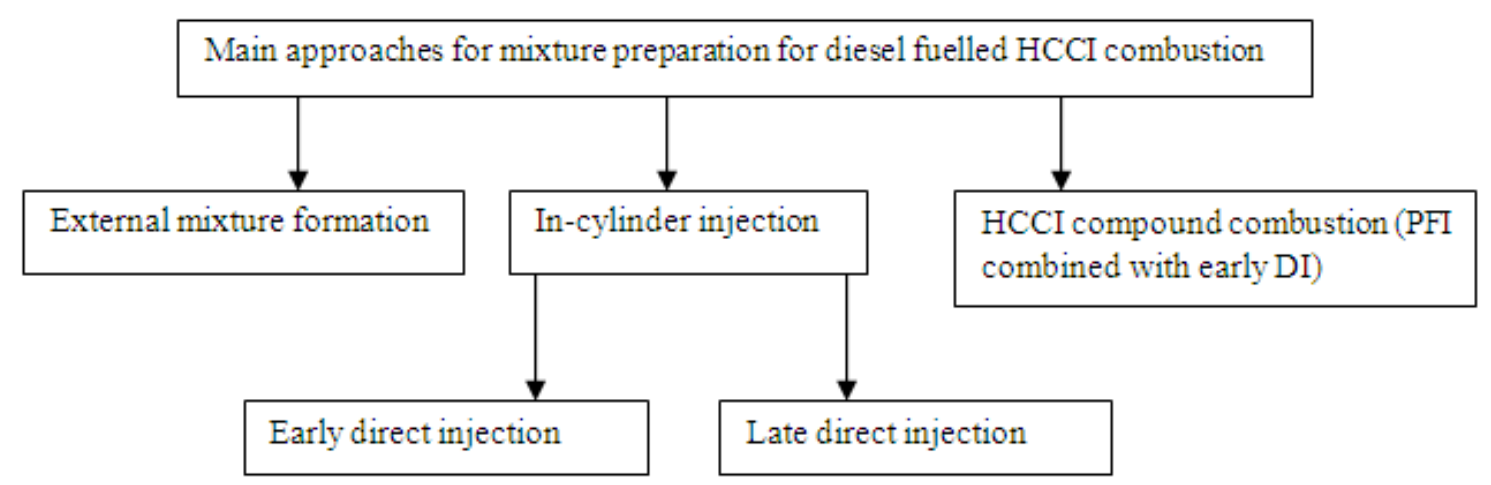

Fig. 3 Main approaches/strategies for mixture preparation for diesel fuelled HCCI combustion [4]

\subsection{External mixture preparation}

The homogeneous mixture preparation external to the cylinder is the most effective as the mixing time available is longer before the start of combustion. The various external mixture preparation strategies have been shown in Fig. 4, which can be classified as port fuel injection (PFI), manifold induction, fumigation, wide open throttle (WOT) carburetion etc. But this strategy of mixture preparation suits more to high volatile fuels like gasoline and alcohols. As the low volatile fuels like diesel cannot easily be vaporised, therefore, this strategy will be effective only with a fuel vaporiser for such fuels. The gaseous fuels can readily be mixed with air and therefore, this method of homogeneous mixture preparation is quite simple, but it may adversely affect the engine volumetric efficiency, if the calorific value of the gas is low [10].

\subsubsection{Port fuel injection (PFI)}

Considering that the longer time span is needed for the homogeneous mixture preparation, the port fuel injection (PFI) is the simplest and the most straight forward method for external mixture preparation, in which injector is incorporated in the intake manifold, very close to the intake valve. The maximum degree of homogenization is obtained by port fuel injection assisted with intake charge preheating $[4,10]$. This strategy enhances the volumetric efficiency and the fuel distribution over the carburetion system. The mixture enters into the cylinder during the suction stroke and the turbulence generated by intake flow improves further homogeneity. This method of mixture preparation has been found to be quite successful with gasoline and alcoholic fuels [26-33]. The main demerit of this strategy is that the start of combustion cannot be controlled by the injection timing. Furthermore, the port fuel injection of heavy fuels with lower volatility leads to poor vaporisation with increased wall wetting [10].

This strategy is similar to that of PFI gasoline HCCI combustion. The basic aim of preheating for diesel HCCI combustion is to enhance fuel evaporation and improve the mixture homogeneity, whereas the purpose of preheating for gasoline HCCI combustion is to increase the compressed temperature at TDC [34]. Recently, an innovative concept called Homogeneous Charge Progressive Combustion (HCPC) has been proposed by Musu et al. to control the diesel-fuelled HCCI combustion [35]. In this concept, the pre-compressed homogeneous mixture is to be prepared outside the engine cylinder and this mixture is to be inducted gradually into the cylinder during the combustion process. In this way, the combustion can be regulated by the transfer flow rate, and high-pressure-rise rates, which are the characteristic of conventional HCCI combustion, can be avoided [36, 37]. In this concept, the negligible soot emission up to equivalence ratios close to 0.85 , with indicated efficiency of about $46 \%$ has been reported [4].

\subsubsection{Port fuel injection (PFI) along with vaporiser}

R. K. Mourya et al. [1] conducted experimental study of ethanol fuelled port injected HCCI combustion with varying intake air temperature $\left(120-150^{\circ} \mathrm{C}\right)$ and different air-fuel ratios. The maximum gas exchange efficiency of $97.47 \%$ and the maximum combustion efficiency of $97.45 \%$ were reported. The maximum indicated thermal efficiency was reported to be $44.78 \%$ at relative air-fuel ratio of 2.5 and the intake air temperature of $120^{\circ} \mathrm{C}$. Higher $\mathrm{HC}$ and $\mathrm{CO}$ emissions but extremely low NOx emission was reported. $\mathrm{HC}$ and $\mathrm{CO}$ emissions increase with the relative air-fuel ratio. Stable HCCI operation was obtained in the air-fuel ratio range of 2-5.

D. Ganesh et al. [5] studied the combustion and the emission characteristics of diesel HCCI with port fuel injection technique assisted with fuel vaporiser on a single cylinder , air cooled DI diesel engine . Cooled EGR $\left(30^{\circ} \mathrm{C}\right)$ in 10,20 and $30 \%$ proportion was applied to control the early ignition. Low NOx and smoke but higher was reported with $30 \%$ EGR.

D. Ganesh et al. [38] investigated diesel fuelled HCCI combustion using external mixture formation technique along with a fuel vaporiser on a single cylinder, four stroke DI diesel engine. They reported significant reduction in ignition delay due to better mixture preparation. Furthermore, considerable reduction in NOx and smoke emissions reported without and with 10\% EGR. 
A. P. Singh et al. [7] applied external mixture formation technique with diesel vaporiser to achieve diesel HCCI combustion. They reported that the diesel HCCI combustion is highly sensitive to air-fuel ratio and EGR. The experiments were conducted at three EGR rates namely 0,10 and $20 \%$ and three different air-fuel ratios $(\lambda=4.95,3.70$ and 2.50). They concluded that the EGR diluted the homogeneous charge and the presence of non-reactive species reduced the rate of combustion. It controls the peak in-cylinder temperature, which is responsible low NOx formation. For richer fuel-air mixtures, EGR was relatively less effective due to dominance of rate of heat release, which was significantly high.

Gajendra Singh et al. [39] investigated biodiesel fuelled HCCI combustion using port fuel injector incorporated with fuel vaporiser. 0, 15 and 30\% EGR was used for controlling the HCCI combustion. Combustion results were more stable for biodiesel HCCI than diesel HCCI due to lower rate of heat release for biodiesel. Reduction in output and the increase in indicated specific fuel consumption (ISFC) reported when biodiesel fraction increased. A small increase in $\mathrm{CO}, \mathrm{HC}$ and smoke emissions observed with increasing biodiesel fraction due to slower rate of evaporation for biodiesel. A considerable decrease in NOx emission reported for biodiesel blend.

Therefore, for low volatility fuels like diesel, for achieving HCCI combustion the port fuel injection (PFI) strategy seems to be effective only with intake fuel or air heating. Though, the full range of operation still remains the unresolved issue.

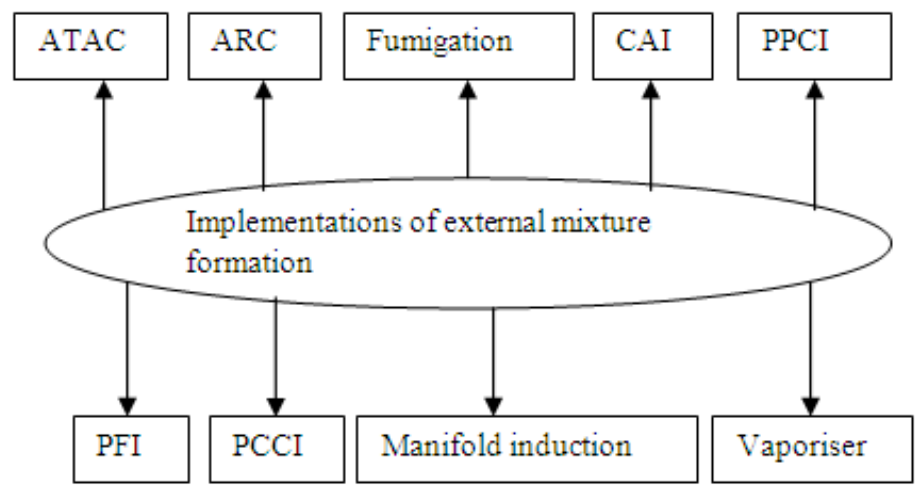

Fig. 4 Early implementations of external mixture formation [10]

\subsubsection{Active-thermo atmosphere combustion (ATAC)}

Initial work related to HCCI combustion was done by Onishi et al. [40] on a two stroke gasoline fuelled engine in year 1979. They tried to increase the combustion stability of the engine. This is known as Active Thermo-Atmosphere Combustion (ATAC). They created conditions that resulted in simultaneous auto-ignition of the cylinder charge without any flame propagation as in conventional SI engine. Considerable reduction in emissions and improvement in fuel economy was reported. Furthermore, it was concluded that with gasoline fuel the stable HCCI combustion can be obtained at a compression ratio of 7.5 and over the speed range of 1000-4000 rpm [41-43]. The same combustion process was shown in an opposed-piston two stroke gasoline engine by Noguchi et al. at the Toyota Motor Company Ltd. and was named "Toyota-Soken (TS) combustion" [44].

\subsubsection{Activated Radical Combustion (ARC)}

Saqaff et al. [45] investigated activated radical combustion (ARC) on two stroke gasoline engine. The exhaust port throttling was tested in the range of 2-16 mm (exhaust port reduction area was 1-8\%) during radical combustion. It was found that, the exhaust gas temperature decreased by approximately $16.7-22.5 \%$ at all engine speeds and loads, whereas the fuel consumption decreased by nearly $11.1-49.8 \%$.

It should be noted that the external mixture formation strategies as shown in Fig. $\mathbf{4}$ can be implemented individually or can be coupled with one or more other strategies and may result in a strategy different than implemented or coupled. Some of the researchers used port fuel injection (PFI) along with a vaporiser to prepare the premixed charge/homogeneous mixture $[5,7,38,39]$.

\subsection{In-cylinder mixture preparation}

\subsubsection{Early direct injection}

The various in-cylinder direct injection strategies have been shown in Fig. 5. Early direct injection strategy shows much more promises to achieve diesel fuelled HCCI combustion. The different early direct injection strategies are hereby discussed in the following subsections:

\subsubsection{PREDIC (PREmixed lean Diesel Combustion)}

In this strategy, the fuel is injected early in the compression stroke, which becomes partly homogeneous mixture and the combustion begins near TDC [46, 47]. Takeda et al. [48] and Nakagome et al. [49] from New ACE institute, Japan did remarkable efforts in the area of early DI-HCCI combustion. They reported very low NOx and smoke emissions, high $\mathrm{HC}$ emissions and significantly high fuel consumption. The 
high emission and the high fuel consumption were reported due to poor combustion efficiency and very advanced combustion phasing. To minimize the wall wetting and the over penetration, three injectors (one at the centre and the two on the sides) were used to control the injection timing and the quantity of each injector independently. Furthermore, the nozzle hole diameter of the centre injector was decreased from $0.17 \mathrm{~mm}$ to 0.08 $\mathrm{mm}$ and the number of holes were increased from 6 to 16 as well as some tests were conducted at different angles with 30 holes of centre injector. In addition, special fuel blends with cetane number of 19 and 40 were developed and tested along with changing the intake temperature and the compression ratio.

\subsubsection{MULDIC (MULtiple stage Diesel Combustion)}

This strategy of early in-cylinder direct injection applies the first injection early in the compression stroke and the second injection just prior to the TDC [10]. Hashizume et al. [50] investigated this mode in which the first stage combustion corresponded to the premixed lean combustion and the second stage combustion corresponded to the diffusion combustion under the high temperature and the low oxygen conditions.

\subsubsection{HiMICS (Homogeneous charge intelligent Multiple Injection Combustion System)}

Similar to MULDIC, in this strategy also the first injection is used early in the compression stroke and the second injection just before the TDC. The HiMICS concept based on pre-mixed compression ignition combustion coupled with a multiple injection was developed by the Hino Motors Ltd. [51]. The pre-mixture was created by a early injection lying between the period from the early stage of the suction stroke to the middle stage of the compression stroke and the later injection after the TDC to oxidise soot. The low emissions of NOx and soot, but high levels of $\mathrm{HC}$ and $\mathrm{CO}$ were reported.

\subsubsection{UNIBUS (UNIform Bulky combustion System)}

This combustion concept was developed by Toyota Motor Corporation, Japan in year 2000. This concept used a combination of an early injection (about $50^{\circ}$ BTDC) and a late injection (about $13^{\circ}$ ATDC) [52]. Yanagihara et al. [52] used piezo-actuator injectors with pintle-type nozzles to reduce the spray penetration in order to limit the over-leaning of the mixture. Most of the data in the paper were with compression ratio 12, presumably to escape the excessively advanced combustion of the premixed combustion. Low levels of fuelling and low injection pressures were found to be most appropriate to limit wall wetting and knocking with this particular type of nozzle. Low PM emissions were reported A luminous flame is not observed, due to the negligible PM available for oxidation, and confirmed by low PM emissions. Furthermore, 60\% EGR level was found to be effective for delaying the HCCI combustion by about $7^{\circ}$ crank angle. Engine was reported to be operated in UNIBUS mode up to half load and half speed.

In another dual-injection strategy, $50 \%$ of the fuel was inducted in a second injection at $13^{\circ} \mathrm{ATDC}$. The second injection considerably improved the combustion efficiency of the early-injected fuel, reducing HC and $\mathrm{CO}$ emissions significantly. So, fuel combustion from the second injection could be assumed as a trigger for a part of the heat release from the early-injected fuel. Though, the second injection increased NOx emissions above the near-zero levels for early injection alone, they were still very low for a diesel engine.

\subsubsection{MULINBUMP}

Su et al. [53-55] proposed a compound diesel HCCI combustion system named MULINBUMP, which coupled premixed combustion with "lean diffusion combustion". The premixed combustion was obtained by the strategy of multi-pulse fuel injection. The start of pulse injection, injection pulse number, injection duration of each pulse and the time gap between the injection pulses were controlled. The purpose of controlling the pulse injection was to limit the spray penetration of the pulse injection in order to avoid the fuel impingement on the cylinder liner, and to improve the mixing rate of each fuel parcel. The last or main injection pulse was arranged near TDC. A flash mixing technology was developed by designing a so-called BUMP combustion chamber fitted with some special bump rings. The combustion of fuel injected in the main injection occurs at much higher air/fuel mixing rate than in a conventional DI diesel engine under the influence of the BUMP combustion chamber, which results in "lean diffusion combustion". The characteristics of auto-ignition and rate of heat release of the premixed fuel of multi-pulse injection were one of the more important aspects that affect engine emissions. By advancing the start timing of multi-pulse injection, noisy auto-ignition could be avoided, but over-advancing of the start timing would result in over-mixing, leading to higher total hydrocarbon (THC) emissions. Furthermore, in the compound combustion mode, the fuel proportion of multi-pulse injection should be high, to avoid noisy auto ignition, which was beneficial in the reduction of NOx emissions. Small amounts of fuel in multi-pulse injection did not help in NOx emissions reduction, but deteriorates the smoke emissions. Compound combustion technology has the promises to achieve HCCI combustion at comparatively wide operating conditions of a diesel engine. Therefore in MULINBUMP compound combustion system at low loads of a diesel engine, there is control of the HCCI combustion process by the multi-pulse fuel injection technique, which can lead to very low NOx and PM emissions and at medium and high loads, the technique of combined premixed combustion with "lean diffusion combustion" is helpful. The mixing rate of fuel and air is improved by combining a high mixing rate combustion chamber with a super high injection pressure, thus achieving rapid mixing. Over the full load range injection modes can be optimized at different conditions by 
regulating multi-pulse injection, thereby clean and high efficiency combustion of the diesel engine can be obtained.

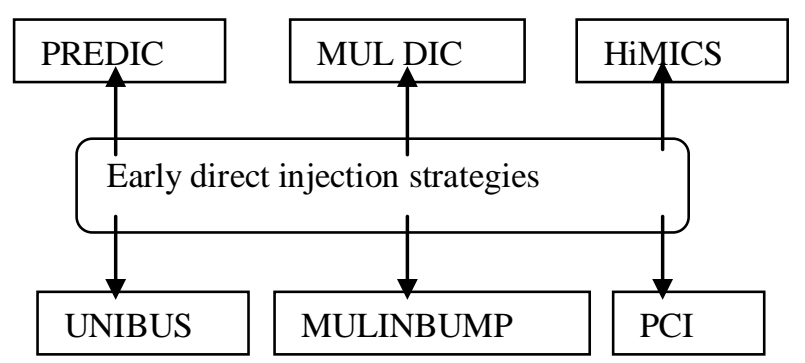

Fig. 5 Early in-cylinder diesel direct injection strategies [10]

\subsubsection{PCI (Premixed Compression Ignition)}

Iwabuchi et al. [56] from the Mitsubishi Motors corporation applied early injection strategy, where premixed compression ignited (PCI) combustion system was adopted in a four stroke, single cylinder, diesel engine. However, the PCI combustion was limited to part load operation and was reported to have more HC emissions with low NOx emissions. The strategy of multiple injections in the HCCI mode is used instead of a single injection strategy, in order to run at high load.

The common feature of above mentioned combustion systems is that the homogenous fuel/air mixture is formed through sprays interacting via injector arrangement and nozzle design [4].

\subsubsection{Late direct injection}

Late direct injection HCCI combustion illustrates the HCCI mode in which the injection takes place at a retarded crank angle than that in) conventional diesel combustion. The classic late injection case of dieselfuelled HCCI combustion is the MK (modulated kinetics) combustion system developed by the Nissan Motor Corporation. In order to obtain the lean homogeneous mixture necessary for HCCI combustion, a long ignition delay and rapid mixing are required. The ignition delay was increased by retarding the injection timing from $7^{\circ}$ BTDC to $3^{\circ}$ ATDC and by applying high levels of EGR, adequate to reduce the oxygen concentration to 15$16 \%$, whereas rapid mixing was obtained by coupling high swirl with toroidal combustion-bowl shape. But the operation range for the first generation MK system was restricted to about one-third of peak torque and half speed. In this mode, NOx emissions were reduced significantly without an increase in PM emissions. Furthermore, combustion noise was also reduced considerably. Besides, it should be noted that with this late-DI HCCI technique, combustion phasing is controlled by injection timing, which is a merit over port fuel injection and early-DI HCCI strategies. In the second generation MK concept, to expand the operating ranges, a combination of prolonged ignition delay, shortened injection duration, higher pressure, a common-rail system, lower compression ratio, increased piston bowl diameter and cooling EGR was employed in the new-generation MK combustion systems. This change significantly reduced HC emissions under cold-engine conditions. The results showed that the second-generation MK system met the full range of everyday driving, fulfilling the second-generation targets of about half load and three-quarters speed with significant reduction of NOx and HC emissions and similar PM emissions as compared to the conventional diesel engine [58-60].

To obtain the premixed combustion, the fuel-air mixture homogeneity before ignition is required in MK combustion concept, which can be achieved by elongating the ignition delay and rapid mixing with a high swirl. In the MK system, there are three features; (i) late fuel injection timing (ii) high levels of EGR and (iii) high swirl ratio [10]. 


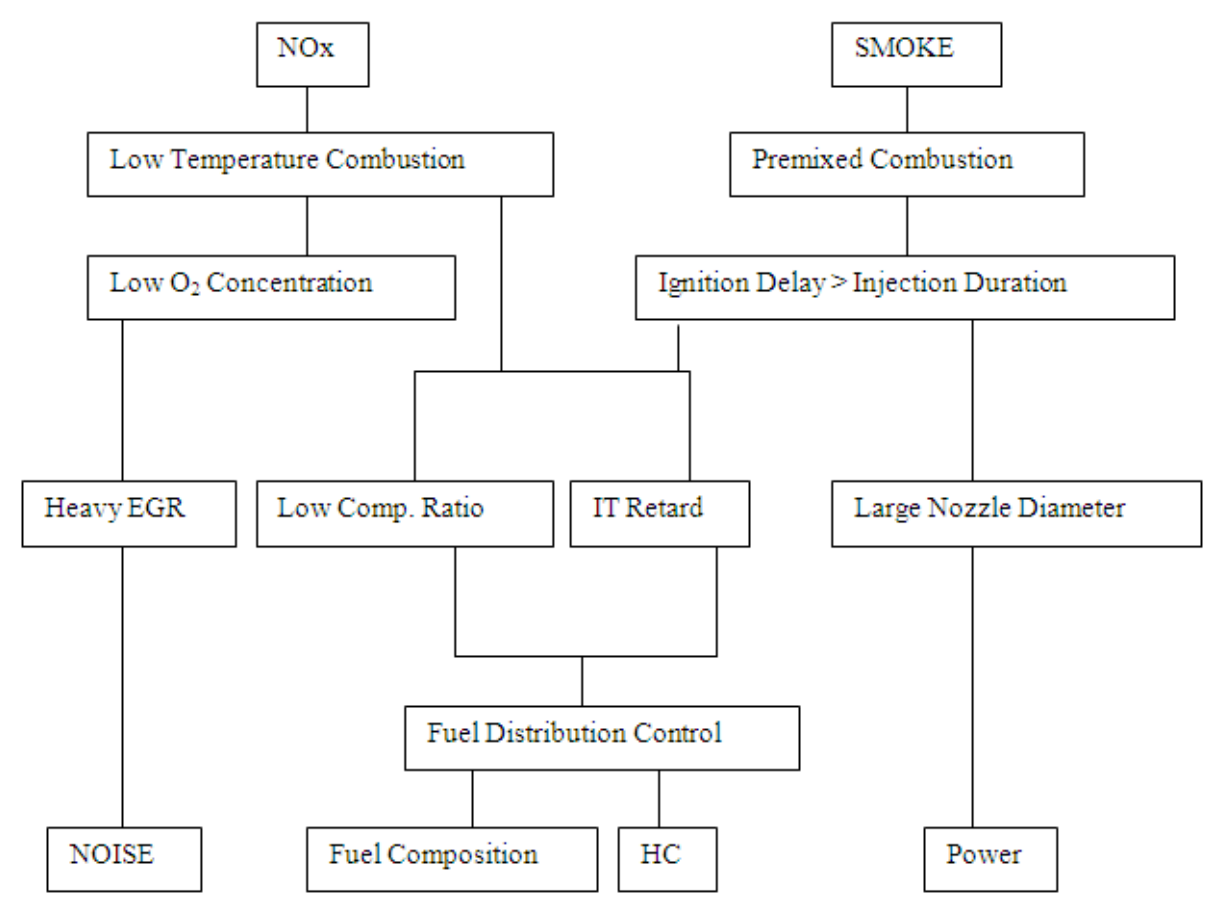

Fig. 6 Schematic of the MK combustion concept [57]

The basic concept of MK combustion is illustrated schematically in Fig. 6 [57]

\subsection{Compound HCCI combustion (Port and in-cylinder direct injection (HCCI-DI)) or Premixed/direct- injected HCCI combustion}

In premixed/direct injected HCCI combustion, the port fuel injection was used for the main fuel supply to form a homogeneous mixture and the in-cylinder direct fuel injection was applied to change the concentration and the location of local fuel-rich regions in order to control HCCI combustion. A homogeneous charge compression ignition diesel combustion (HCDC) system, which is the earliest premixed/direct-injected HCCI combustion system, was given by Odaka et al. [61-64]. In this system, most of the fuel was injected into the intake manifold to create a homogeneous pre-mixture and this premixture was ignited with a small quantity of fuel injected directly into the cylinder. This system reduced both NOx and smoke emissions as compared to the conventional diesel engines. Smoke was reduced near-uniformly with the increase of premixed fuel ratio. Midlam-Mohler et al. [65-67] developed a premixed/direct-injected HCCI combustion system in which Port/manifold fuel was injected using a low pressure atomizer system and in-cylinder direct fuel was injected with the help of a high pressure injection system. The low pressure atomizer system inducts fuel as a premixed lean homogeneous mixture into the cylinder. At low loads, the main torque was obtained from the homogeneous charge fuel created by atomizer and the direct injected fuel is used primarily for ignition; but at high loads, the maximum homogeneous charge fuel was used and direct injection fuelling was increased to full load operation requirement. Small droplet size $(<1 \mu \mathrm{m}$ mean diameter) allowed rapid evaporation in the compression stroke, eliminating the requirement for intake air heating. The results indicated IMEP up to 4.7 bars could be obtained by changing the intake conditions in the speed range of 1600-3200 rpm. Furthermore, the compound HCCI combustion achieved very low NOx and smoke emissions, less than $4 \mathrm{ppm}$ and 0.02 FSN respectively. Foster et al. [68] expanded the HCCI operation by charge stratification achieved by both port and direct fuel injection. The stratification of the charge was changed by two methods (a) by changing the ratio of direct injected fuel to port injected fuel and (b) by delaying the injection timing of the DI injector. Stratified charge showed promises as a feasible enhancement of HCCI combustion at the lean limit. The combustion became more stable with increasing the stratified charge. Berntsson and Denbratt [69] also studied experimentally the control of HCCI combustion by applying premixed/ directed-fuel injection strategy. In this case, the port injection was used for the main fuel supply to form a homogenous mixture with PRF50 as fuel. Both the level of stratification and injection timing of the stratified charge were altered. A larger amount of stratification produced a lower rate of heat release but the main heat release was advanced. Varied injection timing changed the phasing of the main heat release. Therefore, stratification can be used to broaden the ope rating range, due to its effect on combustion phasing and the rate of heat release. Increasing the stratification quantity or late injection timing of the stratified charge resulted in an advanced CA50 timing and more NOx emissions. In the work mentioned above, both the premixed and the direct injected fuel was same, these two fuels can also be different, and the properties of the fuel can also be used to control combustion. Inagaki et al. [70], used gasoline in the intake air port and the diesel fuel was injected directly into the cylinder to act as an ignition trigger at timing before TDC. 
It was reported that the combustion phasing can be controlled by altering the ratios of the two injected fuels, such that the combustion proceeds very mild. Spatial stratification of ignitability in the cylinder prevents the whole charge from igniting instantaneously. By using an intake air boosting system along with dual fuelling, the operating load range, where NOx and smoke emissions were less than $10 \mathrm{ppm}$ and $0.1 \mathrm{FSN}$ respectively, was extended up to an IMEP of 12 bar. Wang Ying et al. [71] investigated HCCI-DI combustion and emissions in Dimethyl ether (DME) fuelled engine. The results indicated that DME engine could be operated at a wider range of loads with a comparatively high brake thermal efficiency at HCCI-DI mode in comparison to HCCI mode. Also $\mathrm{HC}$ and $\mathrm{CO}$ emissions were found to be lower for HCCI-DI as compared to HCCI mode, but increased with an increase in port DME quantity. They further reported that at low loads, NOx emission decreased remarkably with an increase in port DME quantity. But it showed an increasing trend at high loads. NOx emission for HCCI-DI was higher than that for HCCI, but was much lower than that for CIDI mode. Junjun Ma et al. [72] studied experimentally HCCI-DI combustion and emissions with dual fuel on a single cylinder diesel engine at constant speed. They reported that NOx decreased firstly at low premixed ratio and increased at higher premixed ratios. Generally, the NOx of HCCI-DI reduced dramatically as compared to prototype diesel engine. No significant effect of premixed ratio on soot emission was reported, but a peak value was obtained at a certain higher premixed ratio corresponding to the equivalence ratio. The engine performance of HCCI-DI was reported comparable with the prototype diesel engine. The direct injection timing played vital role on the combustion and emission characteristics of HCCI-DI combustion. Premixed ratios in conjunction with the direct injection timing were key enablers for HCCI-DI optimal operating. Xingcai Lu et al. [73] investigated the combustion and emission characteristics of 30\%-50\% (v/v, briefly G30, G40, and G50) gasoline/diesel fuel blends in a compound HCCI combustion mode on a single-cylinder engine. The effect of the gasoline volume in the blends, the premixed ratio, and the overall fuel supply rate on compound HCCI combustion were initially evaluated. In addition, the effects of the intake air boost on G30 compound HCCI combustion were also studied. The experimental results indicated that the maximum heat release rate, maximum in-cylinder pressure, and NOx emissions of G40 and G50 compound HCCI combustion considerably increased as compared to that of G30 compound HCCI combustion. Moreover, it was concluded that the intake air boost has great potential to reduce the NOx and soot emissions of compound HCCI combustion simultaneously. $\mathrm{CO}$ and $\mathrm{HC}$ emissions of optimized G30 compound HCCI combustion with/without boost were comparatively more than that of conventional DICI (direct injection compression ignition) combustion. The NOx and soot emissions of optimized G30 compound HCCI combustion with intake air boost were much lower than those of the DICI diesel engine. Particularly, the NOx emissions were maintained within $100 \mathrm{ppm}$, and the soot emissions were below $10 \%$ at the full load ranges.

\section{Fuel Design and Management for Control of HCCI Combustion}

It has been reported by almost all the researchers that HCCI combustion is essentially depends on the chemical kinetics of fuel/air mixtures under practical engine operating conditions. Fuel physical and chemical properties, as well as spatial and time histories, have significant effects on ignition and combustion. Furthermore, many studies have shown that traditional commercial fuels or single-component fuels cannot fulfil the requirements for HCCI combustion. Therefore, it is necessary to modify or design the molecular structure of fuel, fuel components and composition, and physical and chemical properties to make them more suitable for practical engine combustion. The principles of this concept are depicted in Fig. 7

1. Cetane number: A high cetane number has the significant potential to encourage cold starting, widen the leanburn limit, reduce cycle-to-cycle variation, improve mode transition characteristics, and depress $\mathrm{HC}$ and $\mathrm{CO}$ emissions, but it has an adverse effect on the rich-burn limit.

2. Octane number: Octane number has an effect almost opposite to that of the cetane number.

3. Molecular structure: Paraffin's have only LTHR-enhancing characteristics, aromatics have only LTHRinhibiting effects, olefins and naphthenes have both LTHR-enhancing and -inhibiting effects and the difference between the LTHR enhancing and -inhibiting effects is noticeable.

4. Oxygen content: This parameter has a positive effect that widens the load limit and improves the local combustion efficiency and emissions.

5. Latent heat of evaporation (LHE): A large LHE has positive effect in the suppression of the initial temperature at the starting of the compression stroke, delay of the ignition timing, reduction of the maximum combustion temperature, and partial elimination of knocking combustion.

(6) Boiling point and distillation: A lower boiling point and distillation temperature improves the potential to create homogenous mixtures, removes the local fuel zone, and reduces the maximum combustion temperature and the NOx and PM emissions.

The accurate control of ignition timing, the appropriate combustion rate and centre crank angle, the avoidance of knock, and the preservation of combustion completion are important aspects of HCCI combustion. Therefore, it is essential to reconfigure/modify the 


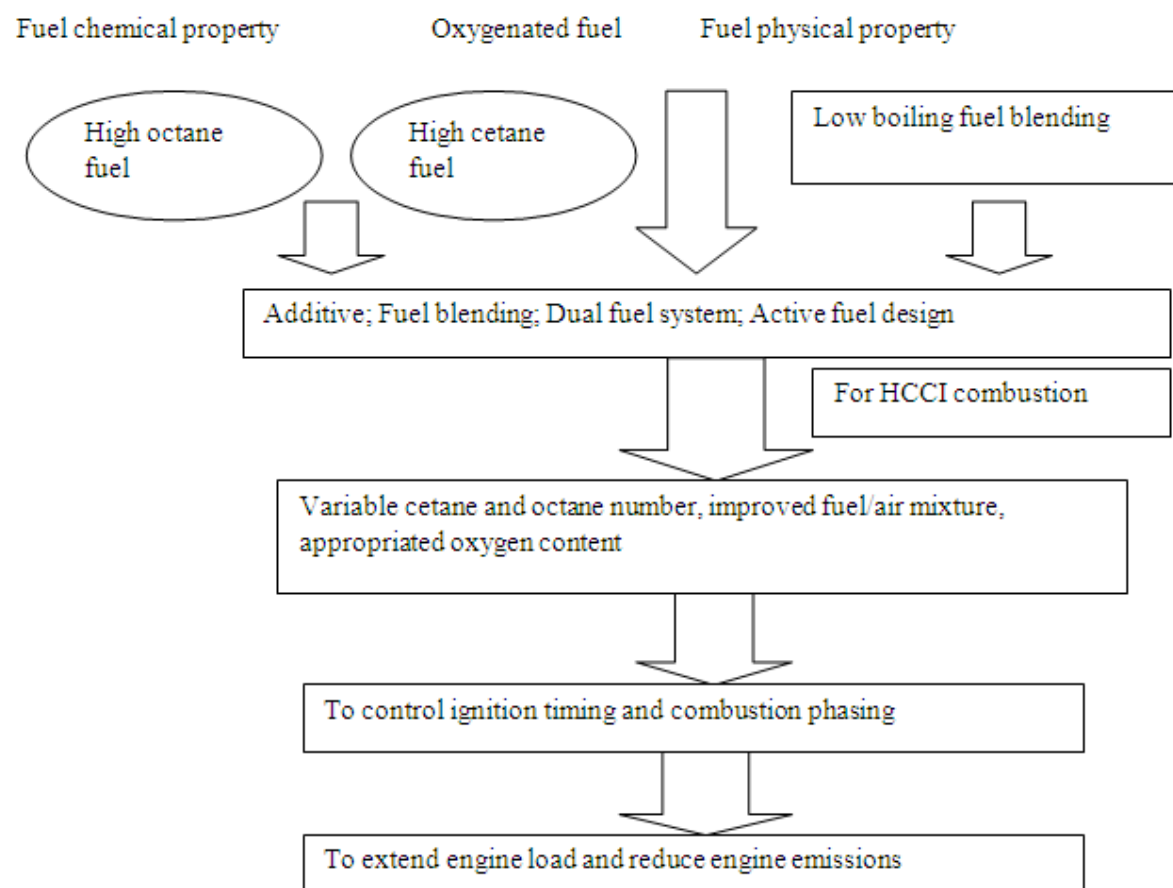

Fig. 7 Fundamental principles of fuel design for HCCI combustion [4]

Fuel properties and compositions to improve the adaptability and compatibility of different fuels for HCCI combustion over a wide operating range. Fuel additives, fuel blending, dual-fuel technology, and optimized fuel proportion in real-time can all be implemented to modify the chemical properties of the in-cylinder mixtures [4].

\section{Control Strategies For Diesel-Fuelled Hcci Combustion}

The combustion phasing in HCCI combustion engines is controlled either by changing the timetemperature history or by altering the reactivity of the mixture [74]. Fig. 8 shows the methods of controlling the HCCI combustion.

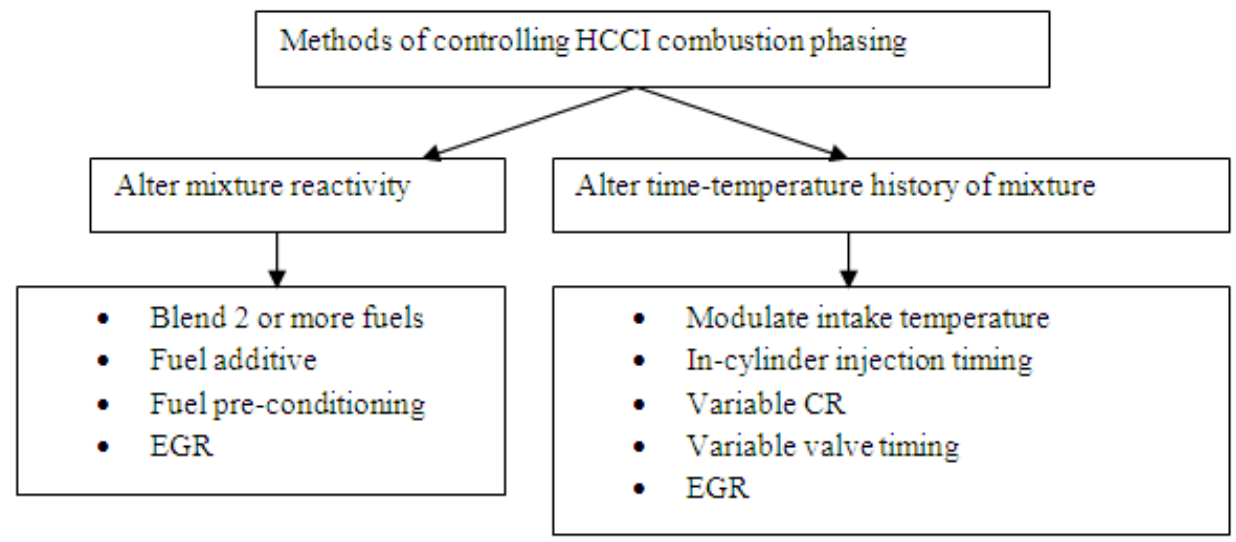

Fig. 8 Methods for controlling HCCI combustion phasing [74]

The parameters illustrated in the first group are used for altering the mixture reactivity, whereas those in the second group can be applied for altering the time-temperature history of the mixture. The reactivity of the mixture can be changed by varying the properties of the fuel, the fuel-air ratio or the amount of oxygen through EGR, whereas the time-temperature history of the mixture can be altered by fuel injection timing, variation of intake air temperature, variation of compression ratio (VCR) and variable valve timing (VVT). However, the preparation of the homogeneous mixture, before the start of ignition is the main purpose of HCCI combustion which can be controlled (a) by enhancing the degree of homogeneity; and (b) by delaying the auto-ignition.

\subsection{Control strategies to improve the mixing rate of fuel and air}

\subsubsection{Ultra high injection pressure with small nozzle holes}

The atomisation of the fuel inside the combustion chamber can be enhanced significantly by using high injection pressures (high velocity of the jet) and by reducing the nozzle hole diameter [10]. Xiangang et al. [75] studied the effects of ultra-high injection pressure (300MPa) and micro-hole nozzle $(\mathrm{d}=0.08 \mathrm{~mm})$ on the flame structure and the soot formation of impinging diesel spray. A bigger flame structure and weak soot formation 
was identified with a micro- hole nozzle at the injection pressures of 200 and $300 \mathrm{MPa}$. No liquid wetting was found for micro-hole nozzle. The fuel-air mixture homogeneity can be improved by increasing the injection pressures and by reducing the diameter of the nozzle hole.

\subsubsection{High swirl ratio}

The air swirl in the combustion chamber also helps to improve the mixing rate between the fuel and air. The BUMP combustion chamber incorporated with the bump rings, used in MULINBUMP combustion system applies a high swirl ratio (3-5) increasing the mixing rate of fuel and air and a high swirl is necessary for the quick homogeneous mixture preparation for combustion [10].

\subsubsection{Pulsed fuel injection}

The early in-cylinder fuel injection requires multi-pulse injections of the total amount of the fuel to be inducted in the cylinder. The lower air density during early CAD injection in the compression stroke results in over penetration of the fuel. In MULDIC combustion system, which applies a two stage fuel injection, the first injection is used for premixed lean combustion, while the second injection is used for diffusion combustion. In the multi-stage fuel injection during early compression stroke, used by the HiMICS and MULINBUMP combustion systems, fuel-air mixing was increased [10].

\subsubsection{High boost pressure}

Supercharging can deliver increased charge density and pressure at all engine speeds while turbo charging depends upon the speed of the engine. The in- cylinder density and volumetric efficiency can be increased using a high boost pressure. The evaporation of the fuel increases with a high intake pressure because of high in-cylinder temperatures. The mixing time decreased with the boost pressure is beneficial in all early injection systems. The combustion efficiency can be increased slightly at high boost levels, and cooled EGR rates were introduced [76].

6.2 Control strategies of extending ignition delay

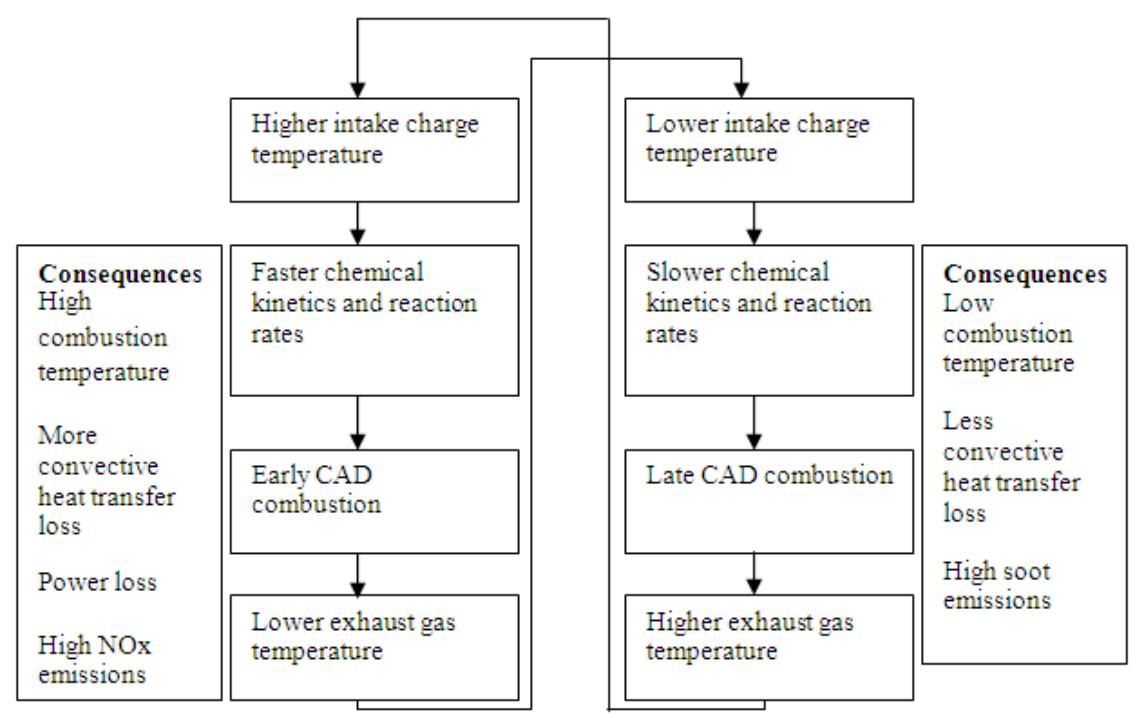

\subsubsection{Variable compression ratio (VCR)}

Fig. 9 Consequences of intake charge temperature and EGR in HCCI engine [10]

The start of ignition (SOI) timing can be delayed by reducing the compression ratio of the diesel engine, but if it is decreased too much then it suffers from the thermal efficiency. Many researchers investigated on VCR engines to delay the auto-ignition timing of the fuel and to explore numerous alternative fuels in HCCI combustion engines. To obtain HCCI combustion decreasing inlet temperatures and lambdas, higher compression ratios were required to maintain proper maximum brake torque and it was concluded that VCR can be used instead of inlet heating [77].Christensen et al. [78] demonstrated a low octane (n-heptane) fuel or a high octane (iso-octane) fuel or a medium octane fuel which one is the most appropriate for the HCCI operation, with reference to the fuel efficiency and the emissions. The compression ratio was changed from 10:1 to 28:1, which shows fuel flexibility of HCCI engine using VCR.

\subsubsection{Charge temperature and equivalence ratio}

The auto-ignition of fuel-air mixture is very sensitive to the change in the intake air temperature. As small as $5-10{ }^{\circ} \mathrm{C}$ change in the intake air temperature can affect the auto-ignition $[79,80]$.Thus, the control of the combustion is very difficult task in order to obtain high efficiency without knock. High cetane fuels like diesel fuel don't require any charge heating, as it can be burnt easily with a compression ratio of 16 . For low cetane fuels, modulation of the intake air temperature is essential to reach its auto-ignition temperature near the TDC for combustion. A higher intake temperature advances combustion but the engine volumetric and thermal 
efficiency can be greately reduced, due to the fact that, if ignition is advanced into the compression stroke, it will result in considerable negative work on the piston.

\subsubsection{Exhaust gas recirculation (EGR)}

The technology of EGR is commonly applied in HCCI combustion because of its high potential to control the auto-ignition of time- temperature history and NOx emission reduction. The EGR can be classified as internal and external EGR. Internal EGR is implemented by the exhaust gas trap (EGT) using the negative valve overlap (NVO) and variable valve timing (VVT) strategies. The most practical way to delay the autoignition in an HCCI engine is by adding high levels of EGR into the intake. The inert gases present in the EGR can be used to control the heat release rate due to its effect on chemical reaction rate, which can delay the autoignition timing. Thus, EGR decreases the heat release rate, and hence lowers the maximum cylinder temperature due to the constituents of EGR (primarily $\mathrm{CO}_{2}$ and $\mathrm{H}_{2} \mathrm{O}$ ) having higher specific heat capacities. The MK combustion system uses a high level of EGR to reduce the NOx emissions up to $98 \%$ less than that of conventional diesel engine. The investigation results of the effect of EGR on ignition delay and the exhaust emissions reported by Gerardo et al. [81] are that (i) it reduces oxygen concentration at the intake, (ii) reduces the adiabatic flame temperature, (iii) increases the ignition delay with as lower pressure rise rate which also improves the combustion noise, (iv) reduces the NOx emissions, and (v) decreases volumetric efficiency and increases the smoke emissions, if its rate is high. Ganesh et al. [5] reported that the EGR has two major effects on $\mathrm{HC}$ emission (a) the induction of some un-burnt $\mathrm{HC}$ with exhaust gases into the next cycle leads to a reduction in $\mathrm{HC}$ emissions, and (b) the decrease of combustion temperature in the cylinder results in an increase in HC emissions. Fang et al. [82] studied on the dual effects of EGR on the BSFC and reported that, the EGR can reduce the pumping loss, and it will lead to slowing down the flame propagation speed, phasing the combustion process away from the TDC of combustion. Fig. 9 depicts the consequences of intake charge temperature on EGR addition. The combustion limit towards leaner air-fuel mixture and the tolerance to the EGR can be considerably extended. The low heating value of lean mixtures and the high heat capacity of EGR can lower the maximum temperature of combustion, which therefore reduces the NOx emission. Up to $95 \%$ reduction in NOx emission has been achieved experimentally $[\mathbf{8 3}, \mathbf{8 4}]$. At low load, the combustion efficiency is the most important one in HCCI combustion which is increased by EGR [85]. The EGR is also used to control the auto-ignition of HCCI combustion. The hot EGR advances the combustion timing, whereas the cold EGR retards it. D. Ganesh et al. [38] used 10\% cooled EGR on a single cylinder, four stroke DI diesel engine operated in HCCI through manifold injection assisted with fuel vaporizer. As compared to the conventional mode of operation, in HCCI with $10 \%$ EGR, a reduction of $80 \%$ and $30 \%$ in NOx and smoke emissions respectively was reported. Lei Shi et al. [86] combined internal and external EGR to control the diesel fuelled HCCI combustion. Internal EGR helped to prepare a homogeneous mixture and reduced the smoke emissions, but lowered the high load limits of HCCI. Cooled external EGR delayed the start of combustion (SOC) effectively, which was very useful for high cetane fuel (diesel) as these fuels can be easily auto-ignite, making the SOC earlier. External EGR expanded the high load limit by avoiding the knock combustion of HCCI at high load. Furthermore, the cooled external EGR reduced the the NOx emissions to a very low level at high load. The $\mathrm{CO}$ emission increased with the EGR rate due to the incomplete combustion because of low temperature and low oxygen concentration in-cylinder.

\subsection{Principles and basic characteristics}

\section{Evolution of Low Temperature Combustion (LTC)}

The key aspects of HCCI combustion depend primarily on the mixture homogeneity, while the thermal efficiency and emission levels of practical engines are determined by the overall combustion event, rather than only by mixture homogeneity. Many studies have found that in-cylinder combustion temperature plays a vital role in the formation and evolution of the emissions as well as the thermal efficiency. Near the year 2000, many researchers introduced a new strategy used to suppress the NOx and the smoke formation by controlling the combustion temperature [87]. It is agreed that one method to avoid both soot and NOx emissions is to keep the temperature during combustion below about $1650 \mathrm{~K}$. In this manner, both the NOx and soot formation regions are completely avoided irrespective of the equivalence ratio. Since then, a new combustion concept known as low-temperature combustion (LTC), produced on a similar ground to HCCI combustion, was proposed by Sandia National Laboratories [88], the University of Illinois at Urbana-Champaign [89], and other research institutes. In LTC combustion concept, high levels of dilution (EGR $>60 \%$ or $<10 \% \mathrm{O}_{2}$ in the intake charge) coupled with flexible fuel injection strategies and strongly turbulent in-cylinder conditions to reduce overall combustion temperatures below the threshold limit of NOx and smoke formation is used. LTC, also known as dilution-controlled combustion, is different from high-temperature combustion (HTC), which is dominated by fuel/air mixing, and it is also different from HCCI combustion, which is dominated by fuel/air chemical kinetics. As compared to HTC, LTC creates a more uniform mixture before spontaneous ignition. However, as compared to HCCI combustion, it applies high levels of EGR and moderate inhomogeneity of the whole mixtures. The 
most prominent feature of LTC is that the turbulence and the mixing play a key role in combustion and emissions as well as in fuel/air chemical kinetics.

The combination of these two combustion modes makes it a unique method that can be implemented to maintain the high thermal efficiency and smooth heat release. LTC is also different from SCCI (or PCCI) combustion as it uses high levels of dilution (EGR $>60 \%$ or $<10 \% \mathrm{O}_{2}$ in the intake charge) coupled with fuel injection strategies besides strong in-cylinder turbulence and mixing to control overall combustion temperatures. The main objective of dilution is to increase the ignition time scale [90], and this increased ignition delay gives time for fuel evaporation and reduces the inhomogeneities in the reactant mixture. Fuel strategies and turbulence are used simultaneously to reduce the mixture preparation timescale, therefore reducing NOx formation from local temperature spikes and soot formation from locally rich mixtures. Furthermore, low oxygen concentration lowers the adiabatic flame temperature significantly [91] leading to the in-cylinder combustion temperature lower than the threshold limit for smoke and NOx formation [92].

\subsection{Key points of LTC}

To achieve LTC in CI engines, the most important requirement is to inject all the fuel into the cylinder and enhance the homogenous mixture formation before the spontaneous ignition. These demands for a longer ignition delay, which is achieved by a high level of EGR or lower oxygen content. Furthermore, high level of incylinder turbulence is used to prepare a uniform mixture. By utilizing high-pressure and multiple-stage fuel injection and heavy EGR or low oxygen content, low-temperature combustion of diesel-like fuels with poor volatility but excellent ignitability was obtained with local and global temperatures below the threshold limit for NOx and soot formation. The main objective of low-temperature combustion strategies is the harmonic combination of fuel injection strategy, in-cylinder flow field, and the level of EGR. For LTC, high-pressure and multiple-stage injection coupled with intensive in-cylinder turbulence was utilized to shorten the required timescale $\left(t_{1}\right)$ for mixture preparation. A high level of EGR or lower oxygen content was used to increase the chemical timescale $\left(\mathrm{t}_{2}\right)$ of the mixture ignition chemistry. Low temperature combustion is achieved as long as $t_{1}<t_{2}$ for the local mixture but $t_{1}>t_{2}$ for the global mixture. For diesel fuels, EGR rates more than $60 \%$ (oxygen content less than 10\%) and an ignition delay of 1.2-1.5 ms are adequate to obtain low-temperature combustion. In LTC mode, NOx and soot emissions are decreased at the cost of increased HC and CO emissions, therefore leading to a marginal reduction in thermal efficiency. LTC may be further optimized by management of physical-chemical properties and fuel components. A moderately reduced fuel cetane number increases $t_{2}$ to some degree, and reduced viscosity and distillation temperature shortens $t_{1}$, whereas the oxygen content in the fuel molecule has the potential to suppress the soot formation. Hence, LTC using oxygenated fuels such as DME and biodiesel can be obtained at a comparatively low EGR rates with improved combustion stability and cycle-to-cycle variation. Furthermore, gasoline/diesel blend fuels suits for low temperature combustion. Extremely-low NOx emissions and smoke-free exhaust were obtained with 13.3\% oxygen content for $40 \%$ gasoline/diesel blend-fuelled LTC. It indicates that the LTC can be achieved with a higher oxygen content or lower EGR rate by modulating the physical-chemical properties of the fuel. [4].

Most important criteria for LTC are not oxygen content or EGR rate but the balance of the mixing time scale and the chemistry time scale $[\mathbf{9 3}, \mathbf{9 4}]$.

\section{Extension of HCCI Combustion Concept - SCCI Combustion 8.1 Strategies and methods of fuel design and management for SCCI combustion}

Till date, it has been very difficult to broaden the HCCI or LTC to full engine load-speed operating ranges with present technical methods and control strategies. To utilize effectively the merits of HCCI and LTC, compound HCCI combustion based on mode transitions or mixture stratification was recently proposed. Compound HCCI combustion based on mode transition refers to the operation of the engine in HCCI mode or LTC mode at low, medium, and cruising load conditions and switching over to SI mode or DICI mode at cold start, idle, and large to full load conditions [95-98]. The mode transition from HCCI to SI, including throttle action, can be obtained in less than ten cycles, but there is fluctuation in switching over from SI to HCCI mode that requires being optimized [99].

Compound HCCI combustion based on mixture stratification is also called stratified-charge compression-ignition (SCCI), premixed compression-ignition (PCI), partial HCCI (pHCCI), and premixed charge compression-ignition (PCCI). In this mode of combustion, the overall combustion history, in-cylinder stratification of the temperature field, mixture concentration, and fuel composition can be adjusted in real-time by modulating the controllable in-cylinder injection timing, spray mode, port fuel injection (PFI) coupled with direct injection, fuel component design and management, and exhaust gas recirculation (EGR). Thus, high thermal efficiency along with ultra-low emissions can be achieved over the full engine operating ranges. For this combustion mode, there is no distinct demarcation between HCCI combustion or LTC and conventional combustion. This mode incorporates the merits of both HCCI combustion or LTC and traditional combustion modes, and the combustion phasing and the combustion rate can be directly and flexibly controlled [100]. In 
fact, absolutely uniform fuel-air mixtures cannot be achieved, irrespective of the mixture preparation methods, and some degree of thermal or mixture inhomogeneities are always present in real HCCI engines. With reference to "stratification", it is commonly agreed that there are three aspects, i.e., temperature field stratification, mixture concentration stratification, and fuel composition stratification, that exist and are coupled in the cylinder.

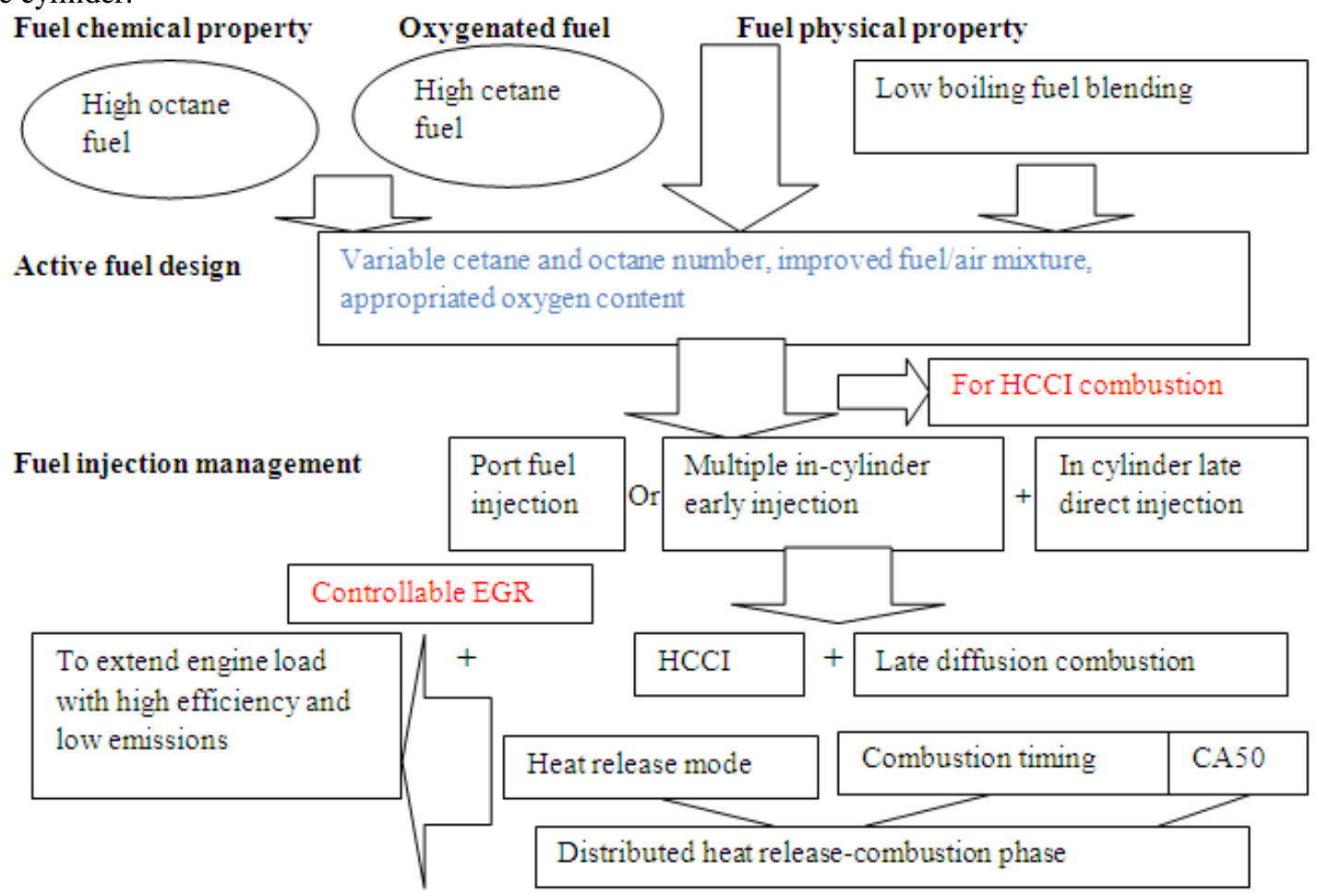

Fig. 10 Fundamental principles of fuel design and management for SCCI combustion [4]

The fundamental principles of fuel design and management for SCCI combustion has been shown in Fig. 10, which can be explained as follows [4]:

1. Fuel physical-chemical properties and molecular components should be designed in real-time on the basis of the operating ranges and selected test fuels.

2. Appropriate fuel concentration stratification should be generated applying fuel supply strategies (for example, port fuel injection combined with in-cylinder direct injection, multi-hole in-cylinder injection and controllable injection timing, injection mode, and split injections).

3. Test fuels with opposite chemical properties should be chosen to be supplied as port injected fuels and directinjected fuels and the spatial local fuel/air concentration should be modulated

4. Controllable EGR should be used as an effective method to suppress the combustion rate and control the peak combustion temperature. By applying this strategy, the onset and heat release of the low temperature reaction, ignition timing and oxidation extent of the second-stage reaction, and the heat release mode and ignition timing of the third-stage can be modulated in a flexible manner.

\subsection{Effect of stratification on SCCI combustion with diesel-like fuels}

The fuels with substantial cool-flame chemistry need immediate and significant compensation as the fuelling rate is changed and additional compensation as the wall temperatures equilibrate. Partial fuel stratification displays promises to achieve a staged combustion event with reduced pressure-rise rates, and hence, partial fuel stratification has the potential to enhance the high-load limits for HCCI/SCCI operation [4].

In-cylinder multiple early injection or port fuel injection coupled with direct injection is effective strategies used to achieve SCCI combustion. Particularly, for port fuel injection or in cylinder early injection of a significant cool-flame chemistry fuel, mixture concentration change provides an effective method for controlling SCCI combustion phasing as the amount of low temperature heat released is proportional to the local equivalence ratio. Therefore, the combustion phasing may be managed within one cycle by varying the injection timing to control the mixture stratification. Besides, fuel stratification can also be applied to adjust the combustion duration using different fuel injection strategies. It infers that the partial fuel stratification can be used to produce a staged auto-ignition event, therefore increasing the combustion duration and reducing the pressure-rise rate [101]. Stratification, thus, can be used to suppress the maximum pressure-rise rate and widen the engine operating load range at the cost of the NOx and CO emissions. It should be remembered that the indicated thermal efficiency of the SCCI combustion is lower than that of conventional DICI engines and pure 
HCCI engines due to the reason that the combustion phasing, heat release mode, and other combustion parameters are not optimized. For these reasons, the challenge of achieving the minimum NOx emissions and maximum thermal efficiency by modulating the stratification and fuel injection timing is a core issue in SCCI combustion. Fig. 11 shows the n-heptane SCCI combustion system with port fuel injection of the PRF mixture. By changing the iso-octane/n-heptane proportions of the premixed fuel, the mixture composition and temperature stratification are formed in the cylinder due to the LTR and HTR of premixed n-heptane. Furthermore, by adjusting the injection timing, the fuel concentration stratification may be changed. Fig. 12 shows the effects of premixed fuel properties and injection timing on SCCI combustion. Particularly, Fig. 12 a displays the effect of fuel supply timing on the heat release rate at a constant overall equivalence ratio and premixed ratio. It is clear that then-heptane delivery timing has a intense effect on the ignition timing and the peak values and their crank angle in the third-stage combustion, but it has only a mild influence on the first- and second-stage combustion. When the n-heptane delivery advance angle is delayed, the peak values, the maximum in-cylinder pressure, and the combustion temperature all decrease. Therefore, the CA50 is delayed significantly and the combustion duration is increased marginally. This has the potential to suppress NOx emissions but leads to a decrease in fuel efficiency and an increase in other emissions. The conclusion is that the in-cylinder fuel injection advance angle plays a key role in the engine-indicated thermal efficiency, and the earlier fuel injection angle has a favourable effect on the indicated thermal efficiency. However, an overly advanced fuel injection angle will result in a abrupt increase in NOx emissions.

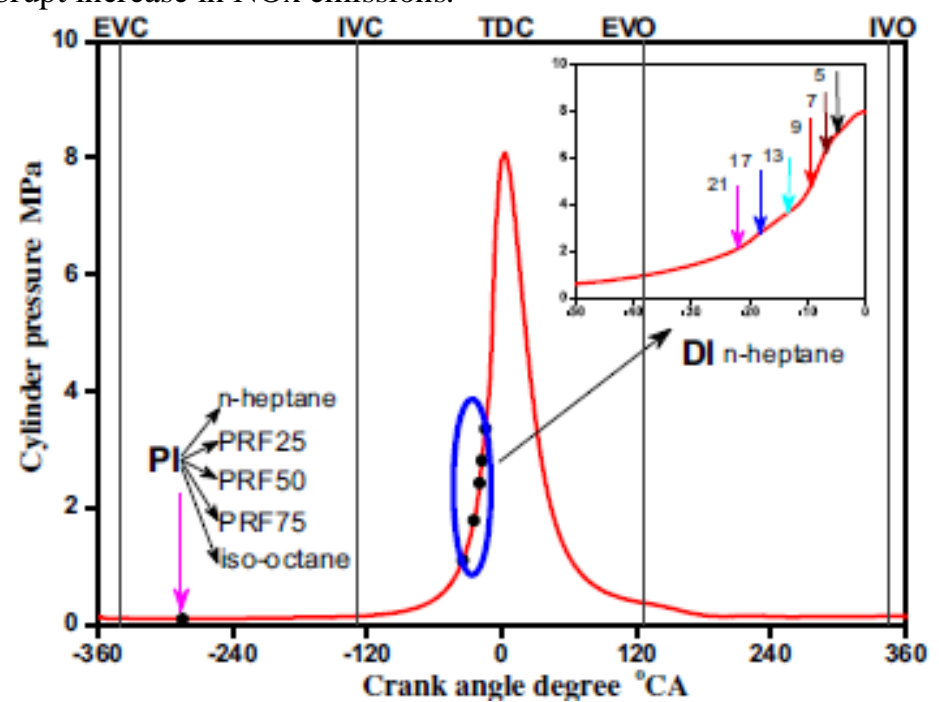

Fig. 11 Stratifications of $\mathrm{n}$-heptane SCCI combustion [102]
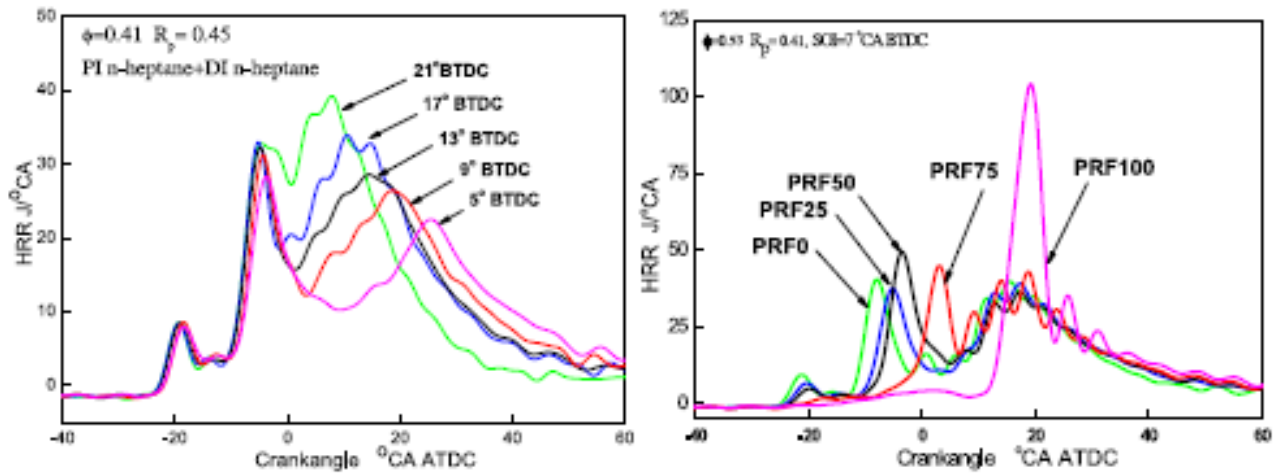

Fig. 12 (a) \& (b) Effect of premixed fuel property and n-heptane injection timing on SCCI combustion [4]

Fig. 12 b shows the effects of premixed fuel properties on the heat release rate (HRR) at a constant overall equivalence ratio, premixed ratio, and fuel injection advance angle. Besides, port fuel injection of isooctane, the overall heat release rate shows the three-stage combustion. The premixed fuel properties have substantial influence on the first- and second-stage combustion phasing and peak points but have negligible effects on the third-stage peak point and its diffusion combustion. With the delaying of the first- and second-stage combustion, the overall heat release is centred on the top dead centre position, which has a favourable effect on thermal efficiency. This also infers that the LTR and HTR of SCCI combustion can be changed by changing the premixed fuel properties. Unlike other combustion behaviour, in the case of iso-octane port fuel injection, the nheptane ignites the premixed isooctane. The heat release displays single-stage combustion behaviour, and the ignition timing of main combustion takes place much later than that of the aforesaid SCCI combustion. By 
optimizing the premixed ratio, premixed fuel properties, and n-heptane injection timing, controllable ignition timing and smooth heat release were achieved. Besides, partial combustion or misfire at the lean limit, as well as knock combustion, was eliminated to some degree, and the operating range was widened to the whole engine speed-load range.

The NOx emissions of SCCI combustion are considerably lower than that of the conventional diesel engine, and the thermal efficiencies are greater than that of DICI and comparable to that of HCCI combustion.

\section{Conclusions}

The HCCI combustion engines have the potential to reduce the NOx and PM emissions simultaneously, while maintaining the thermal efficiency close to that of conventional diesel engine. But in HCCI combustion there are many challenges such as the difficulty in combustion phasing control, misfire at low and knocking at high loads, cold start problem, difficulty in homogeneous mixture preparation, high rate of pressure rise and high level of noise, high level of $\mathrm{HC}$ and $\mathrm{CO}$ emissions etc. The homogeneous mixture preparation and autoignition control are the main issues of the HCCI combustion. In HCCI combustion reduction in NOx and PM emissions simultaneously is made possible by eliminating high-temperature and fuel-rich zones respectively due to lean or diluted mixture obtained through effective homogeneous mixture preparation. Auto-ignition control in HCCI leads to achieve higher thermal efficiency. Port fuel injection (PFI), in-cylinder direct injection and PFI combined with direct injection strategies among others are employed for homogeneous mixture preparation. The port fuel injection strategy has a high degree of mixture homogeneity than other injection strategies, but lacks in start of combustion control. The combustion phasing in HCCI combustion engines is controlled either by altering the time-temperature history or by altering the reactivity of the mixture. The mixture reactivity can be altered by fuel blending, fuel modification or EGR, whereas the time-temperature history of the mixture can be changed by modulating intake temperature, adjusting in-cylinder injection timing, variable compression ratio, variable valve timing and EGR. Furthermore, HCCI combustion as a whole can be controlled by designing and managing the fuel properties appropriately through cetane number, octane number, molecular structure, oxygen content, latent heat of evaporation and boiling and distillation. LTC and SCCI combustion concepts can be regarded as the extension of HCCI combustion concept.

In LTC mode, by utilizing high-pressure and multiple-stage fuel injection and heavy EGR or low oxygen content, low-temperature combustion of diesel-like fuels with poor volatility but excellent ignitability is obtained with local and global temperatures below the threshold limit for NOx and soot formation. But, the most important criteria for LTC are not oxygen content or EGR rate but the balance of the mixing time scale and the chemistry time scale.

In SCCI mode of combustion, the overall combustion history, in-cylinder stratification of the temperature field, mixture concentration, and fuel composition can be adjusted in real-time by modulating the controllable in-cylinder injection timing, spray mode, port fuel injection (PFI) coupled with direct injection, fuel component design and management, and exhaust gas recirculation (EGR). Thus, high thermal efficiency along with ultra-low emissions can be achieved over the full engine operating ranges. This mode possesses the merits of both HCCI combustion or LTC and traditional combustion modes, and the combustion phasing and the combustion rate can be directly and flexibly controlled. Practically, absolutely uniform fuel-air mixtures cannot be achieved, irrespective of the mixture preparation methods, and some degree of thermal or mixture inhomogeneities are always present in real HCCI engines. With reference to "stratification", it is commonly agreed that there are three aspects, i.e., temperature field stratification, mixture concentration stratification, and fuel composition stratification, that exist and are coupled in the cylinder. Furthermore, SCCI combustion can be controlled by proper design and management of the fuel physical-chemical properties and molecular components, fuel concentration stratification applying fuel supply strategies (for example, port fuel injection combined with in-cylinder direct injection, multi-hole in-cylinder injection and controllable injection timing, injection mode, and split injections), test fuels with opposite chemical properties and the controllable EGR.

The characteristic feature of all the advanced combustion modes, such as HCCI, SCCI and LTC is the requirement of preparing a homogenous mixture or controllable stratified mixture before ignition. To this end, a lean fuel/air mixture and/or a controllable high level of exhaust gas recirculation (EGR) are applied to prolong the timescale of the ignition chemistry and port fuel injection or early in-cylinder injection is employed to increase the mixing period. The mixture then undergoes controlled self-ignition near the top dead center (TDC) position during compression stroke. It is to be noted that the entire combustion process lacks a direct method for the control of ignition timing and combustion rate, which are rather controlled mainly by chemical kinetics and, to a lesser extent, by turbulence and mixing. Because of the significant impacts of fuel physical and chemical properties on the ignition and combustion process, fuel design and management has become the most common approach for the control of ignition timing and combustion rate in such advanced combustion modes. 


\section{References}

[1]. Mourya RK, Agarwal AK. Experimental study of combustion and emission characteristics of ethanol fuelled port injected homogeneous charge compression ignition (HCCI) combustion engine. Applied Energy 2011; 88:1169-1180.

[2]. Mourya RK, Agarwal AK. Experimental investigations of performance, combustion and emission characteristics of ethanol and methanol fuelled HCCI engine. Fuel Processing Technology 2014; 126:30-48.

[3]. More FX, Sams T, Cartellieri W. Impact of future exhaust gas emission legislation on the heavy duty truck engine. SAE paper 2001-01-0186; 2001.

[4]. Lu XC, Han D, Huang Z. Fuel design and management for the control of advanced compression-ignition combustion modes. Progress in Energy and Combustion Science 2011; 37: 741-83.

[5]. Ganesh D, Nagarajan G. Homogeneous charge compression ignition (HCCI) combustion of diesel fuel with external mixture formation. Energy 2010; 35: 148-57.

[6]. Yao M, Zheng Z, Liu H. Progress and recent trends in homogeneous charge compression ignition HCCI engines. Progress in Energy and Combustion science 2009; 35:398-437.

[7]. Singh AP, Agarwal AK. Combustion characteristics of diesel HCCI engine: An experimental investigation using external mixture formation technique. Applied Energy 2012; 99: 116-25.

[8]. Zhao F, Asmas TW, Assanis DN, Dec JE, Eng JA, Najt PM. Homogeneous charge compression ignition (HCCI) engines: key research and development issues. USA: Society of Automotive Engineers, Inc; 2003.

[9]. Clean combustion research centre $\langle$ http://ccrc.kaust.edu.sa/Pages/HCCI.aspx $\rangle$.

[10]. Bendu H, Murugan S. Homogeneous charge compression ignition (HCCI) combustion: mixture preparation and control strategies in diesel engines. Renewable and Sustainable Energy Reviews 2014; 38: 732-46.

[11]. Saxena S, Schneider S, Aceves S, Dibble R. Wet ethanol in HCCI engines with exhaust heat recovery to improve the energy balance of ethanol fuels. Appl Energy 2012; 98: 448-57.

[12]. Onishi S, JoS Shoda K, Jo Petal. Active thermo-atmosphere combustion (ATAC) - a new combustion process for internal combustion engines. SAE 790501; 1979.

[13]. Noguchi M, Tanaka Y, Tanaka T, Takeuchi Y. A study on gasoline engine combustion by observation of intermediate reactive products during combustion. SAE 790840; 1979.

[14]. Kitamura T, Ito T, Senda J, Fujimoto H. Mechanism of smokeless diesel combustion with oxygenated fuels based on the dependence of the equivalence ratio and temperature on soot particle formation. Int J Engine Res2002; 3:223-48.

[15]. John E. Dec. Advanced compression-ignition engines- understanding of the in-cylinder processes. Proceeding of the Combustion Institute 2009; 32:2727-2742.

[16]. William de Ojeda et al. Development of a fuel injection strategy for partially premixed compression ignition combustion. SAE paper 2009-01-1527; 2009.

[17]. Zhao H, Peng Z, Ladommatos N. Understanding of controlled auto-ignition combustion in a four stroke gasoline engine. Inst Mech Eng Part D, J Automot Eng 2003; 215: 1297-310.

[18]. US Department of Energy. A report to the U.S. Congress: homogeneous charge compression ignition (HCCI) technology; 2001.

[19]. Lu XC, Chen W, Huang Z. Study on the ignition, combustion, and emissions of HCCI engines fuelled with primary reference fuels. Society of Automotive Engineers; 2005. SAE 2005-01-0155.

[20]. Stanglmaier RH, Roberts CE. Homogeneous charge compression ignition (HCCI): benefits, compromise, and future engine applications. SAE paper 1999; 01-3682; 1999.

[21]. Dec JE. A computational study of the effects of low fuel loading. SAE paper 2002; 01-1309; 2002.

[22]. Eng JA. Characterization of pressure waves in HCCI combustion. SAE paper 2002; 01-2859; 2002.

[23]. Stanglmaier RH, Li J, Matthews RD. The effect of in-cylinder wall wetting location on the HC emissions from SI engines. SAE paper 1999; 01-0502; 1999.

[24]. Hou JX, Qiao XQ. Characterization of knocking combustion in HCCI DME engine using wavelet packet transform. Applied Energy 2010; 87: 1239-46.

[25]. Harada A, Shimazala N, Sator S, Miyamoto T, Akagawa H, Tsujimura K. The effects of mixture formation on premixed lean diesel combustion. SAE paper $980533 ; 1998$.

[26]. Morteza Fathi, Khoshbakhti Saray R, Checkel M David. The influence of exhaust gas recirculation (EGR) on combustion and emissions of $n$-heptane/ natural gas fuelled homogeneous charge compression ignition (HCCI) engines. Appl Energy 2011; 88: 4719-24.

[27]. Tao Li, Kangyao Deng, Haiyong Peng, Chongmin Wu. Effect of partial-heating of the intake port on the mixture preparation and combustion of the first cranking cycle during the cold-start stage of port fuel injection engine. Exp Therm Fluid Sci 2013; 49:14-21.

[28]. Panão MRO, Moreira ALN. Interpreting the influence of fuel spray impact on mixture preparation for HCCI combustion with portfuel injection. Proc Combust Inst 2007; 31:2205-13.

[29]. Srinivas Padala, Minh Khoi Le, Sanghoon Kook, Evatt R. Hawkes. Imaging diagnostics of ethanol port fuel injection sprays for automobile engine applications. Appl Therm Eng 2013; 52:24-37.

[30]. Brusstar M, Stuhldreher M, Swain D, Pidgeon W. High efficiency and low emissions from a port-injected engine with neat alcohol fuels. SAE 2002-01- 2743;2002.

[31]. Mingfa Yao, Zheng Chen, Zunqing Zheng, Bo Zhang, Yuan Xing. Study on the controlling strategies of homogeneous charge compression ignition combustion with fuel of dimethylether and methanol; 2006.p.2046-56.

[32]. Megaritis A, Yap D, Wyszynski ML. Effect of water blending on bioethanol HCCI combustion with forced induction and residual gas trapping. Energy 2007; 32:2396-400.

[33]. Saxena Samveg, Schneider Silvan, Aceves Salvador, Dibble Robert. Wet ethanol in HCCI engines with exhaust heat recovery to improve the energy balance of ethanol fuels. Appl Energy 2012; 98: 448-57.

[34]. Gary AW, Ryan TW. Homogenous charge compression ignition (HCCI) of diesel fuel. Society of Automotive Engineers; 1997. SAE 971676.

[35]. Musu E, Rossi R, Reitz RD. Homogeneous charge progressive combustion (HCPC): CFD study of an innovative diesel HCCI concept. Society of Automotive Engineers; 2009. SAE 2009-01-1344.

[36]. Musu E, Rossi R, Gentili R, Reitz D. Clean diesel combustion by means of the HCPC concept. Society of Automotive Engineers; 2010. SAE 2010-01-1256.

[37]. Musu E, Rossi R, Gentili R, Reitz RD. CFD study of HCPC turbocharged engine. Society of Automotive Engineers; 2010.SAE 2010-01-2107.

[38]. Ganesh D, Nagarajan G, Mohamed Ibrahim M. Study of performance, combustion and emission characteristics of diesel homogeneous charge compression ignition (HCCI) combustion with external mixture formation. Fuel 2008; 87: 3497-503. 
[39]. Singh G, Singh AP, Agarwal AK. Experimental investigations of combustion, performance and emission characteristics of biodiesel fuelled HCCI engine using external mixture formation technique. Sustainable Energy Technologies and Assessments 2014; 6: 11628.

[40]. Onishi S, JoS Shoda K, Jo Petal. Active thermo-atmosphere combustion (ATAC) - a new combustion process for internal combustion engines. SAE 790501;1979.

[41]. Ogume H, Ichikura T, Iida N. A study on adaptability of alternative fuels for lean burn two stroke ATAC engine. SAE 972097; 1997.

[42]. Iida N. Alternative fuels and homogeneous charge compression ignition combustion technology. SAE 972071; 1997.

[43]. Esterlingot E, Guilbert P, Lavy J., Raux S. Thermodynamical and optical analyses of controlled auto-ignition combustion in two stroke engines. SAE 972098; 1997.

[44]. Noguchi M, Tanaka Y, Tanaka T, Takeuchi Y. A study on gasoline engine combustion by observation of intermediate reactive products during combustion. SAE 790840; 1979.

[45]. Saqaff A Al-Kaf, Ahmad S, Abbas HA. Radical combustion: new concept for two stroke engines. J Sci Technol Dev 2000; 17: 919.

[46]. Miyamoto T, Hayashi AK, Harada A, Sasaki S, Akgarwa H, Tsujimura K. Numerical simulation of premixed lean diesel combustion in a DI engine. Comodia 98 Kyoto Japan.

[47]. Shimazaki N, Akagawa H, Tsujimura K. An experimental study of premixed lean diesel combustion. SAE 1999-01-0181; 1999.

[48]. Takeda Y, Keiichi N, Keiichi N. Emission characteristics of premixed lean diesel combustion with extremely early staged fuel injection. SAE paper $961163 ; 1996$.

[49]. Nakagome K, Shimazaki N, Miimura K, Kobayashi S. Combustion and emissions characteristics of premixed lean diesel combustion engine. SAE paper 970898; 1997.

[50]. Hashizume T, Miyamoto T, Akagawa H, Tsujimura K. Combustion and emission characteristics of multiple stage diesel combustion. SAE paper 980505; 1998.

[51]. Yokota H, Kudo YN, H. Kakegawa, T. et al. A new concept for low emission diesel combustion. SAE $970891 ; 1997$.

[52]. Yanagihara H. Ignition timing controlat Toyota "UNIBUS", combustion system. In: Proceedings of the IFP international congress; 2001. p. 35-42.

[53]. Su WH, Lin TJ, Pei YQ. A compound technology for HCCI combustion in a DI diesel engine based on the multi-pulse injection and the BUMP combustion chamber. SAE paper 2003-01-0741; 2003.

[54]. Su WH, Zhang XY, Lin TJ. Study of pulse spray, heat release, emissions and efficiencies in a compound diesel HCCI combustion engine. In: Proceedings of ASME-ICE ASME internal combustion engine division. Fall Technical Conference, ICEF 2004-927; 2004.

[55]. Su WH, Wang H, Liu B. Injection mode modulation for HCCI diesel combustion. SAE paper 2005-01 -0117; 2005.

[56]. Iwabuchi Y, Kawai K, Shoji T, Takeda Y. Trial of new concept diesel combustion system - premixed compression-ignited combustion. SAE 1999-01-0185; 1999.

[57]. Kimura S, Ogawa H, Matsui Y, Enomoto Y. An experimental analysis of low- temperature and premixed combustion for simultaneous reduction of NOx and particulate emissions in direct injection diesel engines. Int J Engine Res 2002; 3: $249-59$.

[58]. Kawashima JI, Ogawa H, Tsuru Y. Research on a variable swirl intake port for 4-valve high-speed DI Diesel engines. SAE paper 982680; 1998 .

[59]. Kimura S, Aoki O, Ogawa H, Muranaka S, Enomoto Y. New combustion concept for ultra-clean and high-efficiency small DI diesel engines. SAE paper 1999-01-3681; 1999.

[60]. Kimura S, Aoki O, Kitahara Y, Aiyoshizawa E. Ultra-clean combustion technology combining a low-temperature and premixed combustion concept for Meeting Future Emission Standards. SAE paper 2000-01-0200; 2000.

[61]. Suzuki H, Koike N, Odaka M. Exhaust purification of diesel engines by homogeneous charge with compression ignition. Part 1: experimental investigation of combustion and exhaust emission behavior under pre-mixed homogeneous charge compression ignition method. SAE paper 970313; 1997.

[62]. Suzuki H, Koike N, Odaka M. Exhaust purification of diesel engines by homogeneous charge with compression ignition. Part 2: analysis of combustion phenomena and NOx formation by numerical simulation with experiment. SAE paper $970315 ; 1997$.

[63]. Suzuki H, Koike N, Odaka M. Combustion control method of homogeneous charge diesel engines. SAE paper 980509; 1998.

[64]. Odaka M, Suzuki H, Koike N, Ishii H. Search for optimizing method of homogeneous charge diesel combustion. SAE paper 199901-0184; 1999.

[65]. Midlam-Mohler S, Guezennec Y, Rizzoni G. Mixed-mode diesel HCCI with external mixture formation: preliminary results. 9th Diesel engine emissions reduction (DDER) workshop; 2003.

[66]. Guezennec Y, Midlam-Mohler S, Rizzoni G. A mixed mode HCCI/DI engine based on a novel heavy fuel atomizer. 8th Diesel engine emissions reduction (DEER) workshop; 2002.

[67]. Midlam-Mohler S. Diesel HCCI with external mixture preparation. 10th Diesel engine emissions reduction (DEER) workshop; 2004.

[68]. Aroonsrisopon T, Werner P, Waldman JO, Sohm V, Foster DE, Morikawa T, et-al Expanding the HCCI operation with the charge stratification. SAE paper 2004-01-1756; 2004.

[69]. Berntsson AW, Denbratt I. HCCI combustion using charge stratification for combustion control. SAE paper 2007-01-0210; 2007.

[70]. Inagaki K, Fuyuto T. Combustion system with premixture-controlled compression ignition. R\&D Rev Toyota CRDL 2006; 41(3):35-46.

[71]. Ying W, Li H, Jie Z, Longbao Z. Study of HCCI-DI combustion and emissions in a DME engine. Fuel 2009; 88:2255-61.

[72]. Ma J, Lu X, Ji L, Huang Z. An experimental study of HCCI-DI combustion and emissions in a diesel engine with dual fuel. International Journal of Thermal Sciences 2008; 47:1235-42.

[73]. Lu XC, Qian Y, Yang Z, Han D, Ji J, Zhou X et al. Experimental study on compound HCCI (homogenous charge compression ignition) combustion fueled with gasoline anddiesel blends. Energy 2014; 64: 707-18.

[74]. Stranglmaier RH, Roberts CE. Homogeneous Charge Compression Ignition (HCCI): benefits, compromises, and future engine applications. SAE 1999-01- 3682; 1999.

[75]. Wang X, Huang Z, Zhang W, Kuti OA, Nishida K. Effects of ultra-high injection pressure and micro-hole nozzle on flame structure and soot formation of impinging diesel spray. Applied Energy 2011; 88:1620-8.

[76]. Au MY, Girard JW, Dibble R, Flowers D, Aceves SM, Joel M, et al. 1.9- Liter four-cylinder HCCI engine operation with exhaust gas recirculation. SAE 2001-01-1894; 2001.

[77]. Law D, Kemp D, Allen J, Kirkpatrick G et al. Controlled combustion in an IC- engine with a fully variable valve train. SAE 2001$01-0251 ; 2001$. 
[78]. Christensen M, Hultqvist A, Johansson B. Demonstrating the multi-fuel capability of a homogeneous charge compression ignition engine with variable compression ratio. SAE 1999-01-3679; 1999.

[79]. Bengtsson J, Gafvert M, Strandh P. Modeling of HCCI engine combustion for control analysis. In:Proceedings of $43^{\text {rd }}$ IEEE conference on decision and control, vol.2;14-17December2004.p.1682-7.

[80]. Tanaka S, Ayala F, Keck JC, Heywood JB. Two-stage ignition in HCCI combustion and HCCI control by fuels and additives. Combust Flame2003; 132: 219-239.

[81]. Valentino G, Corcione FE, Iannuzzi SE, Serra S. Experimental study on performance and emissions of a high speed diesel engine fuelled with n-butanol diesel blends under premixed low temperature combustion. Fuel 2012; 92:295-307.

[82]. Fang-Xi X, Xiao-Ping L, Xin-Chao W, Yan S, Wei H. Research on using EGR and ignition timing to control load of a sparkignition engine fueled with methanol. Appl Therm Eng 2013; 50:1084-91.

[83]. Willand J, Nieberding R, Vent G, Enderle C. The knocking syndrome-its cure and its potential. SAE 982483; 1998.

[84]. Christensen M, Johansson B, Einewall P. Homogeneous Charge Compression Ignition (HCCI) using iso octane, ethanol and natural gas - a comparison with spark ignition operation. SAE 972874; 1997.

[85]. Olsson JO, Tunestal P, Ulfvik J, Johansson B. The effect of cooled EGR on emissions and performance of a turbocharged HCCI engine. SAE 2003-01-0743; 2003.

[86]. Shi L, Cui Y, Deng K, Peng H, Chen Y. Study of low emission homogeneous charge compression ignition (HCCI) engine using combined internal and external exhaust gas recirculation (EGR). Energy 2006: 31; 2665-76.

[87]. Akihama K, Takatori Y, Inagaki K, Sasaki S, Dean AM. Mechanism of the smokeless rich diesel combustion by reducing temperature. Society of Automotive Engineers; 2001. SAE 2001-01-0655.

[88]. Mark P, Musculus B, Dec JE, Pickett M, Idicheria C. In-cylinder imaging of conventional and advanced, low-temperature diesel combustion. 11th diesel engine emissions reduction conference, Chicago IL August 25, 2005.

[89]. Fang TG, Coverdill RE, Lee CF, White RA. Low temperature combustion within a small diesel engine bore high speed direct injection (HSDI). Society of Automotive Engineers; 2005. SAE 2005-01-0919.

[90]. Opat R, Ra RC, Gonzalez DMA, Krieger R, Reitz RD, Foster DE, et al. Investigation of mixing and temperature effects on HC/CO emissions for highly dilute low temperature combustion in a light duty diesel engine. Society of Automotive Engineers; 2007. SAE 2007-01-0193.

[91]. Benajes J, Molina S, Novella R, Amorim R. Study on low temperature combustion for light-duty diesel engines. Energy Fuel 2010;24:355e64.

[92]. Alriksson M, Gjirja S, Denbratt I. The effect of charge air and fuel injection parameters on combustion with high levels of EGR in a HDDI single cylinder diesel engine. Society of Automotive Engineers; 2007. SAE 2007-01-0914.

[93]. Han D, Ickes AM, Assanis DN, Huang Z, Bohac SV. Attainment and load extension of high-efficiency premixed low-temperature combustion with dieseline in a compression ignition engine. Energy Fuel 2010; 24:3517-25.

[94]. Han D, Ickes AM, Assanis DN, Huang Z, Bohac SV. Premixed low temperature combustion of blends of diesel and gasoline in a high speed compression ignition engine. Proc Combust Inst 2011;33:3039-46.

[95]. Santoso H, Matthews J, Cheng W. Managing SI/HCCI dual-mode engine operation. Society of Automotive Engineers; 2005. SAE 2005-01-0162.

[96]. Kulzer A, Hathout JP, Sauer C, Karrelmeyer R, Fischer W, Christ A. Multimode combustion strategies with CAI for a GDI engine. Society of Automotive Engineers; 2007. SAE 2007-01-0214.

[97]. Milovanovic N, Blundell D, Gedge S, Turner J. SI-HCCI-SI mode transition at different engine operating conditions. Society of Automotive Engineers; 2005. SAE 2005-01-0156.

[98]. Koopmans L, Ström H, Lundgren S, Backlund O. Demonstrating a SI-HCCI-SI mode change on a Volvo 5-cylinder electronic valve control engine. Society of Automotive Engineers; 2003. SAE 2003-01-0753.

[99]. Tian GH, Wang Z, Ge QQ, Wang JX, Shuai SJ. Mode switch of SI-HCCI combustion on a GDI engine. Society of Automotive Engineers; 2007. SAE 2007-01-0195.

[100]. Ma JJ, Lu XC, Ji LB, Huang Z. Evaluation of SCCI potentials in comparison to HCCI and conventional DICI combustion using nheptane. Energy Fuel 2008; 2008:954-60.

[101]. Sjöberg M, Dec JE. EGR and intake boost for managing HCCI low-temperature heat release over wide ranges of engine speed. Society of Automotive Engineers; 2007. SAE 2007-01-0051.

[102]. Lu XC, Shen YT, Zhang YB, Zhou XX, Ji LB, Yang Z, et al. Controlled three-stage heat release of stratified charge compression ignition (SCCI) combustion with a two-stage primary reference fuel supply. Fuel 2011; 90: 2026-38. 